\title{
Financing Constraints and Fixed-Term Employment Contracts*
}

\author{
Andrea Caggese and Vicente Cuñat ${ }^{\dagger}$ \\ Universitat Pompeu Fabra
}

27th June 2006

\begin{abstract}
This paper studies the interactions between financing constraints and the employment decisions of firms when both fixed-term and permanent employment contracts are available. We first develop a dynamic model that shows the effects of financing constraints and firing costs on employment decisions. Once calibrated, the model shows that financially constrained firms tend to use more intensely fixed term workers, and to make them absorb a larger fraction of the total employment volatility than financially unconstrained firms do. We test and confirm the predictions of the model on a unique panel data of Italian manufacturing firms with detailed information about the type of workers employed by the firms and about firm financing constraints.
\end{abstract}

*The authors thank Sara de la Rica, Maria Guadalupe, Maia Guell, Barbara Petrongolo, Steve Pischke, Carmelo Salleo, Ernesto Villanueva, attendants to seminars at the Bank of Spain and the European Central Bank and two anonymous referees for their valuable comments and suggestions. All errors are, of course, the authors own responsibility.

†andrea.caggese@upf.edu and vicente.cunat@upf.edu, Pompeu Fabra University, Department of Economics, Calle Ramon Trias Fargas 25-27, 08005, Barcelona, Spain. 


\section{Introduction}

The literature on financing constraints has investigated how financial restrictions may affect firm decisions. Most of the theoretical and empirical literature has analyzed fixed capital investment decisions. ${ }^{1}$ However, there are very few studies on the effects of financing constraints on the employment policies of firms. ${ }^{2}$ The payment of wages and firing costs makes hiring and firing sensitive to the financing frictions that firms face. Moreover the dynamic nature of employment decisions makes firms sensitive also to future expected financing constraints. The aim of this paper is to propose and test empirically a new way of identifying the effects of financing constraints on the employment dynamics of firms by exploiting the different hiring and firing costs of fixed-term contracts and permanent contracts.

We consider the optimal dynamic employment policy of a firm that faces capital market imperfections when one type of labor (fixed-term contracts) is completely flexible and another type (permanent contracts) is subject to firing costs. We assume that the two types of labor are perfect substitutes but permanent employment is relatively more productive. ${ }^{3}$ This implies that a firm without financing constraints would hire permanent workers up to the point where expected firing costs are equal to the productivity gain with respect to temporary workers.

The model shows not only that financing constraints are an important determinant of employment decisions, but also that employment dynamics of fixed term versus permanent workers may help to identify the effect of future expected financing constraints on the real decisions of the firms. More precisely, the model predicts two opposite effects of financing frictions on the composition of employment: on the one hand financing constraints generate a "demand for productivity" effect: they increase the value of internally generated earnings, and thus increase the demand of the more productive permanent workers for those firms that are currently severely financially constrained but expect to be less so in the future. On the other hand future ex-

\footnotetext{
${ }^{1}$ See Hubbard (1998) for a review of this literature.

${ }^{2}$ Exceptions are Nickell and Nicolitsas (1999), Smolny and Winker (1999), Benito and Hernando (2003) and Rendon (2005).

${ }^{3}$ This assumption is equivalent in the model to permanent workers having a higher productivity per unit of salary paid. We do not provide a microfoundation of this assumption. Nonetheless it arises endogenosly in more complex model where the skill of the workers is heterogeneous. E.g. see Cipollone and Guelfi (2003)
} 
pected financing constraints generate a "demand for flexibility" effect: they make firms more vulnerable to liquidity shocks, and increase both the expected volatility of employment and the demand for the more flexible fixed-term workers.

In order to identify these two effects in the empirical data, we solve the model and calibrate a simulated industry that matches the employment dynamics and the volatility of profits of our empirical data. The simulated industry shows that the "demand for flexibility" effect is the most important one, and as a result financing constraints significantly increase the use of fixed-term workers. Moreover the simulations show that financially constrained firms not only hire more fixed-term workers, but also use them to absorb a larger part of the total employment volatility, thereby reducing the volatility of permanent employment. These findings determine a set of robust predictions: 1) financing constraints are predicted to increase both the probability to employ fixed-term workers and the amount of fixed-term workers relative to permanent workers; 2) the positive effect of financing constraints on fixed-term employment is asymmetric, because it is much stronger for firms than increase employment than for firms that decrease it; 3) financing constraints increase the volatility of all types of employment but should increase relatively more the volatility of fixed-term employment than that of permanent employment.

These predictions are tested on a database of small and medium Italian manufacturing firms with balance sheet data from 1995 to 2000. This dataset represents a unique opportunity to verify the joint effect of firing costs, flexible employment contracts and financing imperfections on the labour demand of firms, for several reasons: i) Italy is a country that traditionally has a very high labour protection. ${ }^{4}$ At the same time flexible contracts have been gradually more available to Italian firms in the last 20 years, especially since a new type of fixed-term labour contract was introduced in the mid 1990s. Therefore our dataset is particularly well suited to analyze the effect of the introduction of a flexible labor contract in a heavily regulated environment. ii) The Italian financial system is traditionally underdeveloped. Italian firms face severe capital market imperfections that are only partially corrected by the availability of bank credit as the main source of external finance. iii) The dataset analyzed in this paper contains a unique combination of self-reported measures of financing

\footnotetext{
${ }^{4}$ The OECD 1999 Employment outlook places Italy as the country with the third strictest employment protection legislation among OECD countries in the 1990s.
} 
constraints and information on fixed-term and permanent labor contracts.

The results from the empirical part confirm the predictions of the model that financially constrained firms use more intensely fixed term contracts and have an higher volatility of total employment than financially unconstrained firms do. This higher volatility is partly a mechanical consequence of a higher use of fixed-term contracts (that are unconditionally more volatile) and partly the consequence of a higher volatility of both types of labour among constrained firms. However the empirical results are not precise enough to identify if this increase in volatility is higher for fixed-term contracts. Finally we show, as predicted by the model, that most of the differences between constrained and unconstrained firms are due to different hiring policies, while when firing both types of firms seem very similar. All the results are robust to the inclusion of additional control variables that take into account possible heterogeneity in the empirical data that is not present in the model. The results are also robust to using instrumental variables to correct for the potential endogeneity of the self-reported measure of financing constraints.

The paper is organized as follows: section 2 surveys the related literature. Section 3 illustrates the model. Section 4 presents the empirical analysis. Finally, section 5 concludes.

\section{Related literature}

The findings of this paper complement those in the literature on the effect of employment protection on employment dynamics (Bentolila and Bertola 1990, Bentolila and Saint Paul 1992, Hopenhayn and Rogerson 1993). In particular, the issue of fixedterm labor contracts and their interaction with permanent contracts has attracted significant attention in the preexisting literature. ${ }^{5}$ The European countries where both types of contracts coexist and where several labor reforms have been introduced constitute interesting natural experiments to test the effects of firing costs and labor market regulations. A significant number of articles have studied empirically the different country cases: Spain (Dolado et al, 2002; Alonso-Borrego et al 2005), France (Blanchard and Landier, 2002) and Italy (Kugler and Pica 2004) among many oth-

\footnotetext{
${ }^{5}$ Dolado et al (2002) and Saint Paul (1996) provide a good survey of the relevant theoretical literature on the topic.
} 
ers. All of these papers explore the changes in volatility of employment, the effect of fixed-term contracts on unemployment and the relative use of fixed-term versus permanent contracts. In general they show that, after the introduction of fixed term contracts, fixed-term workers absorb a higher share of the volatility of output. They also show that overall employment volatility increases, but they find ambiguous effects on whether their introduction increases or decreases unemployment. However these papers do not take into account the possible influence of financing constraints. The contribution of this paper is to show not only that financing constraints are an important determinant of fixed-term employment, but also that the interactions between financing frictions and firing costs are important to understand the employment dynamics of firms.

This paper is also related to the literature about the effect of financial imperfections on the labor demand of firms (Nickell and Nicolitsas 1999, Smolny, and Winker 1999, Benito and Hernando 2003). These papers explore at the empirical level the relationship between financing constraints and total employment. In general, they show how the presence of financing constrains may deter hiring. The added value of this paper comes from exploring the interaction between financing constraints, firing costs, and the joint dynamics of fixed-term and permanent employment contracts. That is, in contrast with the previous literature we explicitly model the existence of both types of contracts and show how the presence of financing constraints affects their use. We develop a theoretical model that analyzes the interactions between financial problems and firing costs on the labor demand of firms. The advantage of our approach is that our calibrated structural model provides several clear and unambiguous predictions about the effect of financing constraints on the trade off between permanent and fixed-term labor contracts. In this sense our article can be considered as a bridge between the two strands of the literature mentioned above. ${ }^{6}$

This paper also contributes to the recent literature that investigates new ways of testing for the effect of capital market imperfections at firm level (Almeida and Campello 2006, Whited 2006, Hennessy, Levy, and Whited 2006, Hennessy and Whited 2006, Caggese 2006). In contrast to these papers, that study the effect of

\footnotetext{
${ }^{6}$ Another paper that follows a similar approach is Rendon (2005). The author uses a simulation procedure and compares the effect, on fixed investment and job creation, of relaxing financing constraints as opposed to relaxing labour market rigidities.
} 
financing frictions on fixed and working capital investment decisions, we focus on the effect on employment decisions. Moreover we show that the interactions between financing frictions and employment decisions are helpful to distinguish the effect of current financing problems from the effect of future expected financing constraints. This is important, because usually firm level studies do not distinguish between the effect of current versus future expected financing constraints. One exception is Almeida and Campello (2004), who study the effect of expected financing constraints on the propensity of firms to retain earnings, while we explicitly focus on their effect on the real employment decisions of firms.

\section{The model}

\subsection{Setup}

We consider a risk neutral firm that maximizes the discounted flow of dividends:

$$
V_{t}\left(l_{t}^{p}, \theta_{t}, a_{t}\right)=\max _{l_{t+1}^{p}, l_{t+1}^{f}, b_{t}} d_{t}+\frac{1}{R} E_{t}\left[V_{t+1}\left(l_{t+1}^{p}, \theta_{t+1}, a_{t+1}\right)\right]
$$

Where $V_{t}\left(l_{t}^{p}, \theta_{t}, a_{t}\right)$ is the total discounted value of the firm at time $t$ and $d_{t}$ are dividends. The gross discount rate is $R=1+r$, where $r$ is the market net interest rate.

The state variables that determine the situation of a firm at any given point in time are: $l_{t}^{p}$ is the stock of permanent employment contracts at the beginning of the period; $a_{t}$ is the value of the net cash flow (from operations and maybe financial assets) of the firm at the beginning of the period $t . \theta_{t}$ is the stochastic productivity parameter, with $\theta_{t} \in\left\{\theta_{1}, \ldots, \theta_{N}\right\}$ and $\infty>\theta_{N}>\ldots>\theta_{1}>0$. We assume that $\theta_{t}$ follows a first order Markow process with transition probability $\Gamma\left(\theta^{\prime} / \theta\right)$.

The decision variables of the firm are as follows: $l_{t+1}^{p}$ and $l_{t+1}^{f}$ are the amount of permanent and fixed-term labour contracts respectively. Fixed term contracts only last one year, while permanent contracts are open ended; $b_{t}$ is the face value of one period debt borrowed in period $t$. If negative, it indicates that the firm is a net lender.

The firm uses a concave technology in labor input with a degree of returns to scale equal to $\alpha$ :

$$
y_{t}=\theta_{t}\left(l_{t}^{p}+\rho l_{t}^{f}\right)^{\alpha}
$$




$$
0<\rho<1 ; 0<\alpha<1
$$

$\rho$ is the parameter representing the relative productivity differential between fixedterm and permanent workers. For simplicity we assume that permanent and fixedterm contracts are perfect substitutes and are paid the same wage, normalized to one. They differ in that permanent workers are more skilled, but they can be fired only by paying a fixed cost $F$. Fixed term workers can be fired without restrictions but are relatively less productive than permanent workers. The assumption of identical wages for fixed term and permanent workers is just a normalization. Appendix 1 shows that $l_{t}^{p}$ and $l_{t}^{f}$ can be interpreted as the wage cost of permanent and fixed-term workers in terms of monetary units. It also shows that $\rho$ can be interpreted as the productivity differential of one unit of wage paid to fixed-term workers with respect to one unit of wage paid to permanent workers. In other words, the assumption about $\rho<1$ only implies that the difference in productivity between the two types of contracts is not fully compensated by a wage differential. The timing of the model is as follows:

\begin{tabular}{l|lll|l} 
Time $\mathrm{t}$ & & & Time $\mathrm{t}+1$ \\
\hline$l_{t}^{p}, l_{t}^{f}$ currently employed. & Debt $b_{t-1}$ & $a_{t}$ is determined. & $d_{t}, l_{t+1}^{p}$ and $l_{t+1}^{f}$ & \\
$\theta_{t}, y_{t}$ are realized. & is repaid. & $b_{t} / R$ borrowed. & are determined. &
\end{tabular}

At the beginning of period $t$ the firm has a stock of permanent and fixed-term workers equal to $l_{t}^{p}$ and $l_{t}^{f}$ respectively. The firm observes $\theta_{t}$, realizes revenues $y_{t}$ and repays the debt $b_{t-1}$. The dynamics of the net assets of the firm can therefore be expressed as

$$
a_{t}=y_{t}-b_{t-1}
$$

After production the contract of fixed-term workers ends, and their net hiring in period $t$ is equal to $l_{t+1}^{f}$. On the contrary permanent workers leave the firm at an exogenous separation rate $\delta$. The firm uses financial wealth $a_{t}$ plus new borrowing $b_{t}$ to pay dividends and wages. The budget constraint is the following:

$$
d_{t}+l_{t+1}^{p}+l_{t+1}^{f}-F i_{t}^{p} S_{t}=a_{t}+\frac{b_{t}}{R}
$$

where $F>0$ represents the cost of terminating the contract of one permanent worker. $i_{t}^{p}$ is the gross hiring of permanent workers that can be expressed as $i_{t}^{p}=l_{t+1}^{p}-$ 
$(1-\delta) l_{t}^{p}$. In order to measure firing costs, we define $S_{t}$ as an indicator function that is equal to one when $i_{t}^{p}$ is negative. Therefore $-F i_{t}^{p} S_{t}$ is non negative and is the total amount of firing costs paid by the firm in period $t$. If the firm does not pay the firing cost then $S_{t}=0$, and $i_{t}^{p}$ cannot be negative. Therefore $i_{t}^{p}$ is constrained by the following condition:

$$
\left(1-S_{t}\right) i_{t}^{P} \geq 0
$$

Financing imperfections are present in the form of constraints to external financing. The first constraint is the non negativity of dividends, or in other words that the firm cannot issue new equity:

$$
d_{t} \geq 0
$$

The second constraint is an upper bound on $b_{t}$ that implies that the firm has a borrowing limit.

$$
b_{t} \leq \bar{b}
$$

This constraint imposes some exogenous credit rationing to the firm, but the existing theoretical literature has offered various reasons for its existence. ${ }^{7}$

We add the Lagrange multipliers $\phi_{t}$ and $\lambda_{t}$ to constraints (6) and (7). Moreover without loss of generality we define $\left(1+\phi_{t}\right) \mu_{t}$ as the multiplier of constraint (5). We use equation (4) to substitute $d_{t}$ in equation (1), and we derive the first order conditions of the problem with respect to $b_{t}, l_{t+1}^{f}$ and $l_{t+1}^{p}$ as follows:

$$
1+\phi_{t}=R \lambda_{t}+E_{t}\left(1+\phi_{t+1}\right)
$$

Equation (8) is the first order condition for $b_{t}$. For the following analysis it is useful to solve it forward:

$$
\phi_{t}=R \sum_{j=0}^{\infty} E_{t}\left(\lambda_{t+j}\right)
$$

Equation (9) shows that $\phi_{t}$ is equal to the sum of the current and future costs of a binding financing constraint. Therefore the shadow cost of one additional unit of

\footnotetext{
${ }^{7}$ See for example Siglitz and Weiss (1981) or Ausubel (1991).
} 
external finance is equal to $1+\phi_{t}$. As long as $\phi_{t}>0$, then the return from investing earnings inside the firm is higher than $r$, and the firm does not distribute dividends, so that $d_{t}=0$.

$$
\begin{gathered}
\frac{1}{R} E_{t}\left\{\left(1+\phi_{t+1}\right) \frac{\partial y_{t+1}}{\partial l_{t+1}^{f}}\right\}=1+\phi_{t} \\
\frac{\partial y_{t+1}}{\partial l_{t+1}^{f}} \equiv \rho \alpha \theta_{t}\left(l_{t}^{p}+\rho l_{t}^{f}\right)^{\alpha-1}
\end{gathered}
$$

Equation (10) is the first order condition for $l_{t+1}^{f}$. It holds with equality when the firm hires a positive amount of fixed-term workers. It shows that the expected marginal return of fixed-term workers must be equal to their opportunity cost.

$$
\begin{aligned}
& \frac{1}{R} E_{t}\left[\left(1+\phi_{t+1}\right) \frac{\partial y_{t+1}}{\partial l_{t+1}^{p}}\right]=\left(1+\phi_{t}\right)-\left(1+\phi_{t}\right) \Omega_{t}+c E_{t}\left[\left(1+\phi_{t+1}\right) \Omega_{t+1}\right] \\
& \frac{\partial y_{t+1}}{\partial l_{t+1}^{p}} \equiv \alpha \theta_{t}\left(l_{t}^{p}+\rho l_{t}^{f}\right)^{\alpha-1} \\
& \Omega_{t} \equiv S_{t} F+\left(1-S_{t}\right) \mu_{t} \\
& c \equiv \frac{1}{R}(1-\delta)
\end{aligned}
$$

Equation (12) is the first order condition for $l_{t+1}^{p}$. It always holds with equality, because the assumption about the non-negativity of $\theta_{t}$ and the absence of fixed costs of production imply that it is always optimal to employ a positive number of permanent workers. The term $\Omega_{t}$ is positive when the firm decides to fire or to hoard the excess permanent workers. Therefore the term $E_{t}\left\{\left(1+\phi_{t+1}\right) \Omega_{t+1}\right\}$ is the future expected cost of firing or hoarding permanent workers. Finally, we combine together equations (4) and (7) and we define the maximum investment capacity of the firm as follows:

$$
d_{t}+l_{t+1}^{p}+l_{t+1}^{f}-F i_{t}^{p} S_{t} \leq a_{t}+\frac{\bar{b}}{R}
$$

When the financing constraint is not binding then $\lambda_{t}=0$. In this case equation (9) determines $\phi_{t}$, and equations (10) and (12) determine $l_{t+1}^{p}$ and $l_{t+1}^{f}$. When the financing constraint is binding then equation (16) holds with equality, and together 
with equations (8), (10) and (12) it determines $\lambda_{t}, \phi_{t}, l_{t+1}^{p}$ and $l_{t+1}^{f} \cdot \lambda_{t}$ indirectly affects equations (10) and (12) by increasing the shadow value of money $\phi_{t}$.

Because of the presence of the firing cost, it is useful to analyze the solution of the model separately for the case in which the firm has excess employment from the case in which the firm does not have excess employment.

\subsection{Employment decision when the firm has excess employ- ment}

The firm has an excess of employment when the amount of permanent workers currently employed in the firm is inefficiently high. In this case the firm may choose either to hoard or to fire these workers. Intuitively if the amount of excess workers is relatively small, the firm may choose to hoard all of them, because they may be needed in the future if the firm's prospects improve. Alternatively, if the amount of excess workers is large, it may be necessary to fire some of them.

More formally, let's denote with $\widehat{l}_{t+1}^{p}$ the demand of permanent workers that would be optimal if firing costs were absent in period $t$ but present from period $t+1$ onwards. If the productivity shock is negative and $l_{t}^{p}$ is large then the optimal amount of permanent workers is lower than the amount of currently employed workers: $\widehat{l}_{t+1}^{p}<$ $(1-\delta) l_{t}^{p}$. Because of the presence of firing costs, the firm can either hoard workers and keep $l_{t+1}^{p}=(1-\delta) l_{t}^{p}$, or fire them and pay the fixed cost $F$. In the former case $S_{t}=0$ and $\Omega_{t}=\mu_{t}>0$. In the latter case $S_{t}=1, \mu_{t}=0$ and $\Omega_{t}=F$.

The decision to hoard or to fire the marginal worker depends on the magnitude of $\mu_{t}$ relative to $F$. $\mu_{t}$ measures the cost of hoarding a marginal worker, and it is decreasing in the distance between the optimal unconstrained level of permanent workers and the actual level of workers. That is, as $\widehat{l}_{t+1}^{p}$ converges to $(1-\delta) l_{t}^{p}$ then $\mu_{t}$ converges to zero. Therefore it exists a value of $\widehat{l}_{t+1}^{p}$ sufficiently close to $(1-\delta) l_{t}^{p}$ such that $\mu_{t}$ is smaller than $F$, and the firm chooses $S_{t}=0$ and $l_{t+1}^{p}=(1-\delta) l_{t}^{p}$. The difference $l_{t-1}^{p}-\widehat{l}_{t+1}^{p}$ can be interpreted as labour hoarding. Given the value of $l_{t-1}^{p}$, it is possible to solve equation (10) for $l_{t+1}^{f}$. If the resulting $l_{t+1}^{f}$ is positive, it measures the optimal hiring of fixed-term workers. If it is negative, the optimal hiring of fixed-term workers is zero.

The smaller are $\theta_{t}$ and $\widehat{l}_{t+1}^{p}$, the larger becomes the difference $(1-\delta) l_{t}^{p}-\widehat{l}_{t+1}^{p}$ and the cost $\mu_{t}$ to hoard the marginal worker. Therefore eventually $F<\mu_{t}$, and it 
becomes optimal to fire workers. In this case $S_{t}=1$ and $\widehat{l}_{t+1}^{p}<l_{t+1}^{p}<(1-\delta) l_{t}^{p} . l_{t+1}^{p}$ is determined so that the firm is indifferent between firing or hoarding the marginal fired worker. This implies that $\mu_{t}$ is bounded above by the value of $F$. The difference $(1-\delta) l_{t}^{p}-l_{t+1}^{p}$ is the amount of fired workers, while the difference $l_{t+1}^{p}-\widehat{l}_{t+1}^{p}$ is the amount of hoarded workers. In this case $l_{t+1}^{f}=0$, because it is always optimal to fire fixed-term workers first.

\subsection{Employment decision when the firm does not have an excess of employment}

In this case $S_{t}=\mu_{t}=\Omega_{t}=0$, and the firm has also to decide on the optimal mix between the hiring of permanent and fixed-term workers. This decision depends on a trade off. Permanent workers are more productive, but also costly to fire. Therefore a firm prefers to hire permanent workers if it expects that the probability to fire them in the future is low. The key factor in this decisions is the value of the term $E_{t}\left(\Omega_{t+1}\right)$, the expected cost of firing and hoarding permanent workers in the future. The discussion in section 3.2 makes it clear that $E_{t}\left(\Omega_{t+1}\right)$ increases in $l_{t+1}^{p}$. This is because the higher is $l_{t+1}^{p}$, the more likely it is that the firm will have to hoard or to fire permanent workers in the future. This is formalized in the following proposition:

Proposition 1 Conditional on $\theta_{t}$ and $a_{t}, E_{t}\left(\Omega_{t+1}\right)$ is a continuous and weakly increasing function of $l_{t+1}^{p}$ :

$$
E_{t}\left(\Omega_{t+1} \mid l_{t+1}^{p}=0\right)=0 \quad \frac{\partial E_{t}\left(\Omega_{t+1}\right)}{\partial l_{t+1}^{p}} \geq 0
$$

For a proof, see Appendix 2. For a hiring firm $l_{t+1}^{p}$ and $l_{t+1}^{f}$ are jointly determined by the following two conditions:

$$
\begin{gathered}
E_{t}\left\{\left(1+\phi_{t+1}\right) \frac{\partial y_{t+1}}{\partial l_{t+1}^{f}}\right\}=R\left(1+\phi_{t}\right) \\
E_{t}\left\{\left(1+\phi_{t+1}\right) \frac{\partial y_{t+1}}{\partial l_{t+1}^{p}}\right\}-c E_{t}\left\{\left(1+\phi_{t+1}\right) \Omega_{t+1}\right\}=R\left(1+\phi_{t}\right)
\end{gathered}
$$

Equation (17) simply rearranges equation (10). Equation (18) is derived from equation (12) evaluated for $\mu_{t}=0$ and $S_{t}=0$. Equations (17) and (18) determine the optimal mix between fixed-term and permanent workers for a hiring firm. The 
right hand side is the same for both equations because, as shown in Appendix 1, the amount of labour can be interpreted as measured in wage units. It follows that to hire permanent workers is more profitable than to hire fixed-term workers if:

$$
E_{t}\left\{\left(1+\phi_{t+1}\right) \frac{\partial y_{t+1}}{\partial l_{t+1}^{p}}\right\}-c E_{t}\left\{\left(1+\phi_{t+1}\right) \Omega_{t+1}\right\}>E_{t}\left\{\left(1+\phi_{t+1}\right) \frac{\partial y_{t+1}}{\partial l_{t+1}^{f}}\right\}
$$

We use equations (11) and (10) in (19) to rearrange equation (19) as follows:

$$
\frac{c E_{t}\left\{\left(1+\phi_{t+1}\right) \Omega_{t+1}\right\}}{1+\phi_{t}}<R \frac{1-\rho}{\rho}
$$

Condition (20) has an intuitive interpretation. The right hand side is the marginal productivity gain from the hiring of one additional permanent workers instead of one additional fixed-term worker. The left hand side is the expected marginal firing costs. Therefore a firm that wants to hire one marginal worker will:

$$
\begin{array}{ll}
\text { hire a permanent worker if } & \frac{c E_{t}\left\{\left(1+\phi_{t+1}\right) \Omega_{t+1}\right\}}{1+\phi_{t}}<R \frac{1-\rho}{\rho} \\
\text { hire a fixed-term worker if } & \frac{c E_{t}\left\{\left(1+\phi_{t+1}\right) \Omega_{t+1}\right\}}{1+\phi_{t}}>R \frac{1-\rho}{\rho}
\end{array}
$$

Proposition 1 and condition (21) imply that $l_{t+1}^{p}=0$ cannot be optimal, because the firm prefers to hire permanent workers when its employment level is so low that it does not expect to fire them in the future. But as $l_{t+1}^{p}$ increases, $E_{t}\left(\Omega_{t+1}\right)$ increases, until equation (20) is satisfied with equality. It follows that the optimal level of permanent workers corresponds to the value of $E_{t}\left\{\left(1+\phi_{t+1}\right) \Omega_{t+1}\right\}$ that satisfies equation (20) holding with equality:

$$
\frac{c E_{t}\left\{\left(1+\phi_{t+1}\right) \Omega_{t+1}\right\}}{1+\phi_{t}}=R \frac{1-\rho}{\rho}
$$

Once the level of permanent workers ensures that equation (22) is satisfied, any additional hiring is directed towards fixed-term workers.

\subsection{Financing constraints and the optimal mix between fixed- term and permanent workers.}

The effect of financing constraints on the employment of fixed-term versus permanent workers is in general ambiguous, because of two opposite effects: on the one hand 
financing constraints increase the value of internally generated earning for the firm, and thus increase the demand of the more productive permanent workers. We call firms in which this effect predominates as "type A" firms. On the other hand financing constraints make the firm more vulnerable to liquidity shocks, and increase both the expected volatility of employment and the demand for the more flexible fixed-term workers. We call firms in which this effect predominates as "type B" firms.

In order to understand how these two effects work, consider first a type A firm. this may be a small firm that has profitable opportunities and would like to invest and grow, but it faces financing constraints and can only invest up to the amount of internal funds available. In other words, this firm is currently financially constrained, but it expects to make profits and grow over time. The model predicts that such a firm may hire a smaller fraction of fixed-term workers relative to permanent workers with respect to a similar firm that does not face financing constraints. The reason is that the more a firm is financially constrained the higher is the expected return from reinvesting earnings, the more valuable is the higher productivity of permanent workers. Moreover this firm expects to generate profits, accumulate earnings and grow in size, and it does not expect to fire such workers in the near future.

Second, consider now a type B firm. This may be a larger and more mature firm that is currently generating profits. This firm faces financing frictions but is not currently financially constrained, because it has a sufficient level of internal funds to finance current operations. The model predicts that this firm may hire a larger fraction of fixed-term workers relative to permanent workers, with respect to a similar firm that does not face financing frictions. In order to understand this result, suppose that this firm chooses to hire permanent workers, but afterwards a negative and persistent reduction in productivity (for example an economic downturn) generates losses and reduces its financial wealth. In this case financing constraints have a very negative effect on the firm. First, they may imply that the firm cannot borrow to finance the payment of the wages. In other words, the firm may be forced to fire some permanent workers even though it would be more efficient to hoard them. Second, firing such workers has an higher opportunity cost, because internal funds become more valuable as financial wealth decreases and financing constraints become more intense. This amplification effect between financing constraints and expected firing costs increases ex ante the incentive to hire fixed-term rather than permanent workers. 
In other words, a firm that is afraid of future financing constraints values more the flexibility of fixed-term workers with respect to a firm that does not face financing frictions.

The relative importance of these two effects described above determines whether, on aggregate, financing constraints lead to a higher or lower use of fixed-term contracts. More formally, the effect of financing constraints on the optimal ratio between fixed-term and permanent workers can be studied by focusing on the equilibrium condition (22). We rearrange it as follows:

$$
A_{t}\left[E_{t}\left(\Omega_{t+1}\right)+B_{t}\right]=R \frac{1-\rho}{\rho}
$$

Where:

$$
A_{t} \equiv c \frac{E_{t}\left(1+\phi_{t+1}\right)}{1+\phi_{t}} \quad \text { and } \quad B_{t} \equiv \frac{\operatorname{cov}\left(\phi_{t+1}, \Omega_{t+1}\right)}{E_{t}\left(1+\phi_{t+1}\right)}
$$

Equation (23) shows that financing constraints have two counteracting effects on the optimal hiring of a firm. The term $A_{t}$ summarizes the effect of a currently binding financing constraint. The term $B_{t}$ summarizes the effect of future expected financing constraints. The term $A_{t}$ increases in $\frac{E_{t}\left(1+\phi_{t+1}\right)}{1+\phi_{t}}$, which is the ratio between the expected shadow value of money in period $t+1$ and the shadow value of money in period $t$. When the firm is not currently constrained $\left(\lambda_{t}=0\right)$, then $\frac{E_{t}\left(1+\phi_{t+1}\right)}{1+\phi_{t}}=$ 1. Conversely $\frac{E_{t}\left(1+\phi_{t+1}\right)}{1+\phi_{t}}$ decreases the higher is the intensity of current financing constraints relative to future expected financing constraints. In this case the value of $E_{t}\left(\Omega_{t+1}\right)$ that satisfies equation $(23)$ is larger, and the optimal ratio $\frac{l_{t+1}^{F}}{l_{t+1}^{P}}$ is smaller. Therefore the term $A_{t}$ reflects the fact that the benefits of permanent workers in terms of their higher productivity are received immediately, while the expected firing costs will be paid in the future.

The sign of the term $B_{t}$ depends on the sign of $\operatorname{cov}\left(\phi_{t+1}, \Omega_{t+1}\right)$, the covariance between the expected shadow value of money and the expected costs of firing permanent workers. This covariance is positive when the firm expects that, in case financing conditions will worsen in the future, it will become very costly to fire or to hoard permanent workers. The larger is $B_{t}$, the smaller is the value of $E_{t}\left(\Omega_{t+1}\right)$ that satisfies equation (23), the larger is the ratio $\frac{l_{t+1}^{F}}{l_{t+1}^{P}}$. 


\subsection{Predictions}

The above discussion suggests that the interactions between financing constraints, firing costs, and the hiring of fixed-term and permanent workers may help to identify the effect of financing constraints on the dynamics of firm employment.

We expect the presence of financing frictions to reduce the use of fixed-term workers when the term $A_{t}$ is large relative to $B_{t}$ for most firms. In other words, when financing frictions only affect small and young growing firms, that are financially constrained today but expect to be less so in the future. Instead we expected financing frictions to increase the use of fixed-term workers when $B_{t}$ is large relative to $A_{t}$ for most firms. In this case, even though few firms are severely financially constrained, all firms may enter cyclical phases of high intensity of financing constraints, and therefore they hire fixed-term workers in order to reduce the costs of future expected financing problems.

In order to estimate which of the two effects dominates empirically, we use the following strategy. First, we calibrate the parameters of the model to match the moments estimated from our sample of Italian firms. We focus on the statistics that are key to determine the two effects above, such as the volatility and growth of employment, the volatility of revenues, the average fraction of fixed-term over permanent workers and the average fraction of constrained firms. Second, we simulate the artificial industry and we evaluate the effect of financing constraints on employment dynamics. Third, we use the simulation results to derive several predictions about the employment dynamics of financially constrained versus unconstrained firms, that can be verified with the empirical data. ${ }^{8}$

\footnotetext{
${ }^{8}$ It is important to notice that some simplifying assumptions of our model may induce to overestimate the magnitude of the term $A_{t}$ and underestimate the positive effect of financing frictions on the use of fixed term workers. More specifically two additional effects not present in the model may be at work: i) the higher productivity of permanent workers may depend on their own human capital investment directed to build up job specific skills. In this case the gain in productivity may not be immediate and take time to materialize; ii) permanent workers may be more skilled workers that are more difficult to recruit, thus they are subject to an additional hiring cost. Therefore, in equilibrium, their higher productivity repays gradually the higher costs spent filling the vacancy. Both effects reduce the attractiveness of permanent workers for constrained firms, because they delay the net productivity gain from using permanent workers.
} 


\subsection{Calibration}

We solve the model and simulate the activity of many artificial firms, in order to derive testable implications about the effects of financing constraints on the employment dynamics of the firms. The calibration of the parameters matches the volatility of employment and the volatility of revenues of our sample of Italian firms.

In order to allow the simulated industry to match the key features of the empirical data we introduce two changes in the basic model illustrated in the previous section: i) with an exogenous probability $1-\gamma$ the firm's technology becomes useless, the firm is liquidated and the value of the assets is distributed as dividends. We assume that a liquidated firm does not have to pay the firing costs for the permanent workers, so that equation (1) is modified as follows:

$$
V_{t}\left(l_{t}^{p}, \theta_{t}, a_{t}\right)=\max _{l_{t+1}^{p}, l_{t+1}^{f}, b_{t}} \gamma d_{t}+(1-\gamma) a_{t}+\frac{1}{R} E_{t}\left[V_{t+1}\left(l_{t+1}^{p}, \theta_{t+1}, a_{t+1}\right)\right]
$$

This exogenous exit probability is necessary in order to generate a simulated industry in which a fraction of firms is financially constrained in equilibrium. If $\gamma=1$ and firms are infinitely lived then they eventually accumulate enough wealth to become unconstrained, and the simulated industry always converges to a stationary distribution of financially unconstrained firms, no matter how tight the borrowing constraint (7) is; ii) we model the idiosyncratic shock $\theta_{t}$ as a combination of a persistent and an i.i.d. shock (in the remainder of the paper we include the subscript $i$ to indicate the $i-t h$ firm):

$$
\theta_{t}=\theta_{t}^{I} \theta_{i, t}^{P}
$$

where $\theta_{i, t}^{P}$ is a persistent shock:

$$
\begin{aligned}
\ln \theta_{i, t}^{P}= & v \ln \theta_{i, t-1}^{P}+\varepsilon_{i, t}^{P} \quad \text { where } 0<v<1 \\
& \varepsilon_{i, t}^{P} \sim \operatorname{iid}\left(0, \sigma_{P}^{2}\right) \text { for all } i
\end{aligned}
$$

and $\theta_{i, t}^{I}$ as an i.i.d. shock:

$$
\begin{gathered}
\ln \theta_{i, t}^{I}=\varepsilon_{i, t}^{I} \\
\varepsilon_{i, t}^{I} \sim i i d\left(0, \sigma_{I}^{2}\right) \text { for all } i
\end{gathered}
$$

The persistent shock $\theta^{P}$ is necessary to match the dynamics of employment. The i.i.d. shock $\theta^{I}$ matches the volatility of revenues. Both shocks are important because 
they allow the simulated firms to have realistic dynamics of both employment and financial wealth. If we only allow for the persistent shock $\theta^{P}$ (by setting $\sigma_{I}^{2}=0$ ) then we cannot match the wealth dynamics observed in the data, because simulated firms would have too low volatility of revenues and also would almost never realize negative net income, which instead is realized in $24 \%$ of the firm-year observations in the sample.

One possible shortcoming of the model is that we assume the shock $\theta$ to be stationary, while the productivity of the firms in our empirical data may be non stationary. However, we argue that this is not likely to be a problem in interpreting the results of the model and the empirical analysis, for at least three reasons. First, the time series dimension of the empirical data is very short, and therefore nonstationarity is not likely to significantly bias the empirical results. Second, in the model the shock $\theta_{i, t}^{P}$ is stationary but very persistent, and the entry-exit of firms generate growth dynamics very similar to the dynamics observed in the data, because all firms are created small, and conditional on surviving they increase in size and become less financially constrained. In fact the simulated industry matches well the average growth rate of employment at the firm level observed in the data. Third, in Appendix 3 we illustrate in detail the implications of assuming a non stationary shock $\theta$. We show that the predictions of the model regarding the optimal ratio between fixed-term and permanent workers are not affected by this change, while the effect on the other predictions of the model is likely to be small and accounted for by the control variables included in the empirical analysis in the next section.

The parameters are calibrated as follows: $r=0.03$, corresponding to $3 \%$ interest rate; $\alpha$, the return to scale parameter, is equal to $0.95 ; \rho$ matches the average fraction of fixed-term to permanent workers; $\delta$ corresponds to an exogenous separation rate of $2.2 \%$ permanent workers per year. $v$ and $\sigma_{P}$ match the average and the standard deviation of the ratio of gross hiring over total employment; $\sigma_{I}$ matches the standard deviation of the sales/assets ratio. $\gamma$ matches the average age of the firms in the sample. Finally, $F$ matches the average job destruction rate, which includes voluntary separations, firing of permanent contracts and expiration of fixed-term contracts. The calibrated value is $10 \%$ of the yearly wage. This is lower that the estimated average firing cost for Italy in 2005 according to the OECD, which is $32 \%$ of the yearly salary. A plausible explanation of this difference is that in reality firing costs are a function 
of the duration of the contract. For example the average firing cost increases to $80 \%$ of yearly salary after 20 years worked. Therefore the value of $10 \%$ is plausible as an estimate of the firing costs of the more recent workers, those who would be fired in reality in case of a negative shock. Nevertheless, since already with a firing cost of $10 \%$ firms almost never voluntarily fire workers in the simulated industry (the average firing rate is only $0.65 \%$ ), an increase in $F$ does not significantly change the qualitative results from the simulations.

Table 1 summarizes the parameters choices, and shows that the model matches the empirical moments reasonably well.

\section{Table 1 about here}

\subsection{Simulation results}

We use the solution of the model to simulate 100.000 firm-year observations. We sort firms into groups of more financially constrained firms using the average value of the Lagrangian multiplier $\bar{\lambda}_{i}=\sum_{i=1}^{T_{i}} \lambda_{i, t}$. Where $T_{i}$ is the number of years of operation of firm $i$ and $\lambda_{i, t}$ measures the shadow cost of a binding financing constraint for firm $i$ in period $t$. In the benchmark case we consider as constrained the group of firms with the $33 \%$ higher value of $\bar{\lambda}_{i}$, and as unconstrained the complementary group of firms. The average value of $\phi_{t}$, the premium in the shadow value of money for the firm, is equal to $9.5 \%$ for the constrained sample and $2.0 \%$ for the complementary sample.

The first two columns in Table 2 illustrate the employment dynamics of the constrained firms and the complementary group. The third column shows the difference across groups. The statistics are computed following the same method used in Table 1 , by pooling all the observations in each group. This method is justified by the fact that in the simulations all firms are ex ante identical and operate the same technology. Nonetheless in the fourth column we show the percentage difference across groups when the statistics are instead computed on a balanced sample of simulated firms, following a procedure analogous to the procedure used on the empirical data in the next section. The comparison of the last two columns of Table 2 shows that the qualitative predictions of the model do not depend on the specific method used to compute the statistics. 
Table 2 compares the volatility of total employment and of permanent and fixedterm workers for the group of most constrained firms and the complementary sample. The firms in the two groups differ both in their average size and in their average use of the two contracts. Therefore volatilities are computed as coefficients of variation, following the same procedure that will be used in the empirical section. Moreover the coefficient of variation of fixed-term workers is computed conditional on having a positive amount of such workers. This way we distinguish the probability to hire fixed-term workers from the volatility of fixed-term workers conditional on them being currently used by the firms. The table also reports the volatility of fixed-term and permanent workers as scaled by total employment.

Table 2 shows that constrained firms have an higher volatility of permanent workers than the complementary sample. The table also shows that constrained firms are more likely to hoard rather than to fire permanent workers. This should reduce the volatility of permanent employment. On the other hand constrained firms change employment in response to a liquidity shock that changes financial wealth and the investment capacity of the firm, while unconstrained firms are not sensitive to changes in financial wealth. This effect increases the volatility of permanent workers, and it dominates on the previous effect.

More importantly, constrained firms hire more fixed-term workers. This is because future expected financing constraints matter in the simulated industry, and as a consequence fixed-term employment is mostly used by financially fragile firms, that are either constrained or will be financially constrained in the future conditional on a negative shock. Moreover, fixed-term employment is also substantially more volatile for constrained firms. It follows that while permanent employment is only $6.4 \%$ more volatile, total employment is $16 \%$ more volatile for constrained firms than for the complementary sample.

\section{Table 2 about here}

Table 3 illustrates the sensitivity of the model's predictions to different criteria to select the group of financially constrained firms. It shows that the narrower is the definition of financially constrained firms, the larger are the differences between constrained and unconstrained firms. More importantly, the qualitative predictions of the model are confirmed for all the different sample splitting criteria. 


\section{Table 3 about here}

Table 4 estimates the average ratio between fixed-term and permanent workers for firms that increase or decrease employment. These expanding firms are identified by the dummy hire $_{i t}$, which is equal to 1 if the firm $i$ increases employment from period $t-1$ to period $t$ and is equal to zero otherwise. Moreover contracting firms are identified by the dummy fire $_{i t}$, which is equal to 1 if the firm $i$ decreased employment from period $t-1$ to period $t$ and is equal to zero otherwise. This dummy variable is called "fire" for simplicity, because firms can reduce employment not only by firing, but also by reducing fixed-term employment or by not replacing voluntary separations in permanent employment. The results show that the difference between financially constrained and unconstrained firms is almost entirely driven by the behaviour of firms that increase employment. For example among firms that do not hire the average ratio Fixed term workers/Permanent workers is equal to $2.4 \%$ and $2 \%$ for the $20 \%$ most constrained firms and the complementary sample respectively. Conversely for the firms that hire these ratios are equal to $11.3 \%$ and $7 \%$ respectively. ${ }^{9}$ This latter difference is high because financially constrained firms use more intensely fixed workers especially during expansion phases. The intuition is as follows: an expanding firm that faces future expected financing constraints has an higher probability to be forced to cut investment and employment in the future conditional on a negative liquidity shock. As a consequence such a firm relies much more on fixed-term workers than an unconstrained firms.

Tables 2, 3 and 4 show that financially constrained firms hire more fixed-term workers than unconstrained firms, and that their employment is more volatile. It is a well know result in the employment literature that the presence of fixed-term workers increases the volatility of employment, because it increases the ability of the firm to change employment policy in response to exogenous shocks. ${ }^{10}$.

In this respect the added value of our model is to show that financing constraints are an important determinant of the decision to hire fixed-term workers in the first place. Moreover our model also shows that not only financially constrained firms

\footnotetext{
${ }^{9}$ The constant is equal to zero because in the simulated sample the only firms that keep employment constant over time are very wealthy firms that never hire fixed term workers.

${ }^{10}$ See Bentolila and Saint Paul (1992) for a general theoretical explanation of this effect. See also Garcia-Serrano (1998) and Amuedo-Dorantes and Malo (2005) among others for some empirical evidence.
} 
hire more fixed-term workers, but also that conditional on hiring such workers their fixed-term employment is more volatile than the fixed-term employment of the unconstrained firms. In other words, the positive effect of financing constraints on employment volatility is stronger for fixed-term employment than for permanent employment.

This result may in principle depend on two distinct factors: on the one hand it may be that financing constraints increase the volatility of fixed-term workers independently on what happens to permanent workers. On the other hand it may be that financially constrained firms rely more on fixed term workers and less on permanent workers to absorb exogenous shocks with respect to what financially unconstrained firms do.

\section{Table 4 about here}

Tables 5 and 6 investigate more in depth on this issue. They compare employment dynamics in two industries. One is the industry with the benchmark parameters. The other is identical to the first, except that it does not allow for the presence of fixed-term workers. ${ }^{11}$ Table 5 shows that the presence of fixed-term contracts increases volatility of employment in the industry by around $5 \%$. This number is small because the average amount of fixed-term workers is relatively small (around 4\%) in the benchmark calibration. Interestingly, the introduction of fixed-term contracts reduces the volatility of permanent employment by $8 \%$ for constrained firms, while it does not affect such volatility for the complementary sample. This difference is quite striking, given that both groups of firms hire a significant amount of fixed-term workers. The introduction of fixed-term workers reduces the volatility of permanent workers because it allows constrained firms to use fixed-term workers to absorb the fluctuations in employment induced by financing frictions. This also explains why average firing costs decrease by almost $50 \%$ for constrained firms after the introduction of fixed-term contract, while they decrease only by $20 \%$ for unconstrained firms. The consequence is that without fixed-term workers permanent employment is $15 \%$ more volatile for more constrained firms than for the complementary sample. Conversely

\footnotetext{
${ }^{11}$ Because the model is in partial equilibrium, the simulated industry without fixed term workers is an imprecise calibration of the equilibrium that would prevail in the real industry if fixed workers were not available. Nonetheless the bias is relatively small because the total amount of workers in the industries with and without fixed term workers is nearly identical, as the intruduction of fixed term workers increase both average job creation and job destruction by a similar amount.
} 
with fixed-term workers is only $6 \%$ more volatile. Therefore financially constrained firms not only hire more fixed-term workers, but also make them absorb a larger part of the total employment volatility, thereby reducing the volatility of permanent workers.

\section{Table 5 about here}

Table 6 shows the elasticity of employment dynamics to a change in the borrowing limit. It compares the industries with and without fixed-term workers. The results show that relaxing the borrowing limit has a much greater effect in the industry without fixed-term workers. A $1 \%$ increase in the borrowing limit reduces the fraction of constrained firms by $0.36 \%$ in the industry without fixed-term workers and only by $0.12 \%$ in the industry with fixed-term workers. Moreover it reduces the volatility of employment by $3.5 \%$ in the industry with fixed-term workers and by $20 \%$ in the industry without fixed-term workers. Therefore the presence of fixed-term workers provides additional flexibility to the employment decisions of the firms and reduces the impact of financing frictions on them.

Table 6 also shows that an increase in borrowing capacity reduces the volatility of fixed-term workers, but it increases the ratio of fixed-term over permanent workers. Figure 1 shows that the increase in the ratio depends on two counteracting effects. On the one hand the increase in borrowing capacity reduces expected financing constraints of more wealthy and less constrained firms, and reduces their fixed-term employment. On the other hand it increases the ability of constrained firms to hire fixed-term workers following a positive productivity shock. The second effect dominates in equilibrium for the parameter values of the benchmark calibration, but as the borrowing capacity of firms further increases the first effect eventually dominates, and the ratio between fixed-term and permanent workers decreases in the borrowing limit.

\section{Table 6 about here}




\section{Empirical Analysis}

The results illustrated in the previous section allow us to formulate the following predictions regarding the empirical relationship between financing frictions and employment dynamics:

i) Both the probability to hire fixed-term workers and the amount of fixed-term workers relative to permanent workers are higher for more financially constrained firms.

ii) The higher use of fixed-term workers among constrained firms is almost entirely due to constrained firms hiring more fixed-term workers when they increase employment.

iii) Total employment, permanent employment and especially fixed-term employment are more volatile for more financially constrained firms than for the other firms.

This section verifies these predictions on the empirical data, and is divided in four parts. Section 4.1 describes the data and variables used; section 4.2 explores the validity of the financing constraint measure used later on and shows the first stage of the instrumental variables approach used later on; finally section 4.3 tests the predictions of our theoretical model.

\subsection{Data and Specification}

To test the empirical predictions of the model we use the dataset of the Mediocredito Centrale surveys. The dataset contains a representative sample of Small and Medium Italian manufacturing firms. It is an incomplete panel with two main sources of information gathered in two different surveys:

i) Yearly balance sheet data and profit and loss statements from 1989 to 2000 .

ii) Qualitative information from four surveys conducted in 1992, 1995, 1998 and 2001. Each survey reports information about the activity of the firm in the three previous years.

The availability of both information about the firm accounts and qualitative answers in the surveys makes this dataset very useful to study how the perceptions and expectations of firms affect their investment and production decisions. ${ }^{12}$ Each survey

\footnotetext{
${ }^{12}$ Examples of papers that use the Mediocredito Centrale survey in this spirit are Basile, Giunta and Nugent (2003), Piga (2002) and Angelini and Generale (2005)
} 
is conducted on a representative sample of the population of small and medium manufacturing firms (smaller than 500 employees). The samples are selected balancing the criterion of randomness with the one of continuity. The firms in each survey contain three consecutive years of data. After the third year $2 / 3$ of the sample is replaced and the new sample is then kept for the three following years.

For the analysis of this paper we restrict our sample to the last 6 years of the dataset (1995-2000). This is because of two main reasons. First, a new type of fixedterm contracts became regulated and started to be widely used in the second half of the $90 \mathrm{~s}$. Second, detailed information about all the different types of employment is only available in the 1998 and 2001 surveys. We also restrict ourselves to firms with 10 or more workers, as the regulation for permanent workers of smaller firms differs in Italy and makes it much easier to fire permanent workers for them. We also drop firms that were subject to a merger or acquisition and firms that split due to spin-offs or divestitures. That leaves us with 18783 firm-year observations for which we have valid information about the use of fixed-term and permanent contracts. ${ }^{13}$

This dataset is particularly well suited for our analysis for several reasons: in the first place the introduction of fixed-term contracts in Italy means the coexistence of two different contractual agreements that have very different firing costs. This matches exactly the situation described in our theoretical model. At the same time, the database is a representative sample of manufacturing firms of different industries and sizes, with detailed information about a number of aspects of the firm as well as direct questions that try to elicit the existence of financing constraints affecting a particular firm.

The calibration of the model predicts a differential use of fixed-term and permanent contracts depending on whether firms are financially constrained or not. To test these predictions we run different regressions in which the dependent variables are: the ratio of fixed-term workers over total employment ratio ${ }_{i t}$; the coefficient of variation of total employment cvemployment ${ }_{i t}$ measured as the standard deviation of ratio $_{i t}$ calculated over a three year window that coincides with each wave and

\footnotetext{
${ }^{13} 80 \%$ of the firms appear in the sample for 3 consecutive years and $15 \%$ for 6 consecutive years, the rest have different number of observations because the firms were created during the sample time or because some firm-year observations are dropped due to outlier cutting or missing values in the dependent or independent variables.
} 
divided over the mean of ratio $_{i t}$ on that same period. ${ }^{14}$ We also use as additional dependent variables the coefficient of variation of the number of fixed-term contracts cvfixedterm $_{i}$ and the coefficient of variation of permanent contracts cvpermanent $_{i}$. Given that there are several firms that use zero fixed-term contracts in two or three years of a three year "window", these coefficients of variation would not be appropriate measures if we used such a short period. ${ }^{15}$ For this reason these two last variables are calculated across all six years and therefore they only vary cross sectionally.

Our independent variables of interest are related to the financing constraints that the firm faces. To construct our main measure of financing constraints we consider the questions in the Survey where each firm is asked:

i) Whether it had a loan application turned down recently.

ii) Whether it desires more credit at the market interest rate.

iii) Whether it would be willing to pay an higher interest rate than the market rate in order to obtain credit.

These questions are asked only in the 1998 and the 2001 surveys, which refer to the activity in period 1995-1997 and 1998-2000 respectively.

We use this information to construct our main measure of financing constraints self declared $_{i t}$, which takes value 1 for period $t$ if firm $i$ declares to have any of the problems (i) to (iii) and takes value zero otherwise. According to this measure $16 \%$ of the firms declare to be financially constrained. ${ }^{16} \quad 17$

Given that firm size is a major determinant of financing constraints, with smaller firms facing higher problems when it comes to getting additional funding, we also use as an alternative measure of financing constraints the size of the firm. For that we construct a dummy variable small $_{i t}$ that takes value one if assets are smaller than 5700 million lira. ${ }^{18}$ This threshold splits the sample roughly in two equal parts.

\footnotetext{
${ }^{14}$ Therefore cvemployment $t_{i t}$ varies cross sectionally and takes two different values along time for the 1995-1997 period and the 1998-2000 period.

${ }^{15}$ For firms with all observations equal to zero, the coefficient of variation is not defined. For firms with two observations equal to zero and a positive one have a coefficient of variation of 1.73 regardless of the value of their only positive observation. This is a quite high value and could be artificially driving the results if we used a three year window.

${ }^{16}$ We drop from the sample 55 firm-observations that do not respond to any of the questions. They represent less than $0.3 \%$ of the total observations. The distribution of non-respondents to each question is as follows: question i) $8 \%$, question ii) $0.4 \%$ and question iii) $15 \%$

${ }^{17}$ The cross sectional standard deviation of the self declared $_{i t}$ variable is 0.36 and its time series standard deviation is 0.096 .

${ }^{18} 5700$ million lira correspond to $\$ 2.94 \mathrm{~m}$ according to December 1999 exchange rates.
} 
We include in all the regressions a number of control variables to account for possible heterogeneities between firms that are not present in the theoretical model. The first control variable is fixed capital ${ }_{i t}$ that is constructed as fixed assets of the firm divided by the number of employees and controls for the fact that the model abstracts from the different intensities of labour versus fixed capital. The second control variable, sdsales $i$ is the standard deviation of the sales of the firm calculated over a three year window that coincides with each survey wave and corrects for the heterogeneity of the productivity shock across firms. Finally we include growth assets $s_{i t}$ which is the annual growth rate of assets calculated year by year. Appendix 3 shows that this variable controls for the effect of possible non-stationarities. We also include in all the regressions year and sector dummies. ${ }^{19}$ The qualitative results of the regressions are robust to the exclusion of the set of control variables from the balance sheet. ${ }^{20}$

To summarize this section, a generic specification of the regressions in this empirical part can be written as:

$$
y_{i t}=\gamma \text { constrained }_{i t}+\beta X_{i t}+d_{s}+d_{t}+\varepsilon_{i t}
$$

Where $y_{i t}$ is one of the variables that measure fixed-term contracts use, volatility of employment or the volatility of each type of contract, constrained $d_{i t}$ is either the small $_{i t}$ variable or the self declared ${ }_{i t}$ measure that is occasionally instrumented as explained in the next section, $d_{s}$ and $d_{t}$ are year and sector dummies and $\beta X_{i t}$ is a vector of controls composed by fixed capital $_{i t}$, sdsales $_{i t}$ and growth $_{\text {assets }}$. $_{\text {. }}$

Table 7 shows the summary statistics for the different variables used in the rest

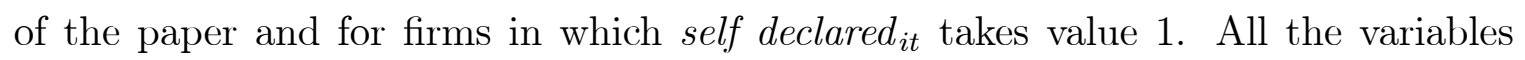
calculated as ratios are subject to the presence of outliers whenever the denominator is abnormally small. For this reason, we drop the observations corresponding to the top $1 \%$ of each of these variables (top and bottom $1 \%$ when the variable is not constrained to be positive) when calculating the statistics of Table 7 and whenever they are used in a regression.

\section{Table 7 about here}

\footnotetext{
${ }^{19}$ Sectors defined as 2 digit ATECO91 classification.

${ }^{20}$ This is shown in Appendix 4, where we report the coefficients of all the regressions excluding all the control variables except the year and sector dummies.
} 
The ratio of fixed-term workers to permanent workers is $3.9 \%$ for all firms and $4.9 \%$ for firms that declare to be constrained, so this unconditional analysis is consistent with the predictions of an higher use of fixed-term contracts among constrained firms. ${ }^{21}$ It also shows that constrained firms are smaller, and have a higher volatility of total employment. In the following sections we first provide evidence that the measure of financing constraints is related to effective financing restrictions faced by firms. We then test the predictions of the model with respect to financing constraints and the use of fixed-term employment contracts.

\subsection{Validation of the Financing Constraints Measure}

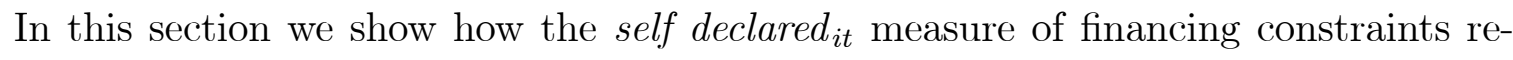
lates to other indirect measures of financing frictions. The reason for this analysis is twofold. In the first place, we want to assess the validity of the self declared variable as a reliable measure of financing constraints. In the second place we will use some of the indirect measures of financing frictions as instrumental variables that correct for potential measurement errors in self declared $_{i t}{ }^{22}$ For this purpose we run a regression in which the dependent variable is the financing constraints variable (self declared ${ }_{i t}$ ) and the independent variables are as follows: The first variable used measures the coverage ratio of interest payments coverage $_{i t}$, calculated according to the following formula: coverage $i_{i t}=\left(\pi_{i, t}-i_{i, t}\right) /\left(\pi_{i, t}+i_{i, t}\right)$ where $\pi_{i, t}$ is profits before interest and taxes and $i_{i, t}$ is interest paid on debt. The variable takes value zero whenever the ratio is negative. ${ }^{23}$ The second variable used reflects the net liquid

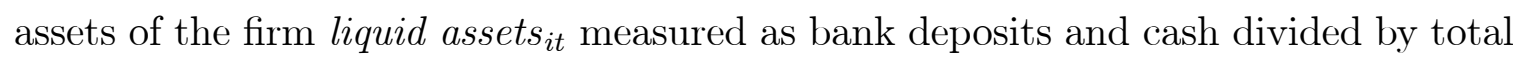
assets. The relationship of this measure with the existence of financing constraints is controversial. In general, firms with more liquid assets are less likely to be financially

\footnotetext{
${ }^{21}$ The OECD reports an average amount of fixed term workers in Italy of $7.5 \%$ in 1995 and $11 \%$ in 2000. This is higher than in our sample, which only includes manufacturing firms, while fixed term workers are more prominent in the services sector. It is important to note that this is a relatively high growth period in Italy, with an average annual GDP growth rate of $1.9 \%$ that lead to a small reduction of unemployment rates (11.2\% in 1995 vs 10.1 in 2000 )

${ }^{22}$ It is important to remark here that the more qualitative data about self-declared financing constraints and the quantitative balance sheet data come from different surveys, so measurement errors are less likely to be correlated between surveys.

${ }^{23}$ Note that this is not the standard definition of a coverage ratio, which is normally defined as interest payments over profits before interest payments. The qualitative results using the more standard variable are qualitatively similar to the ones obtained here, but we find that our variable is also a good measure of financing constraints while being more stable and having less extreme values.
} 
constrained; however it is also known that firms occasionally hoard liquidity when they expect future negative liquidity shocks that could be correlated with financing constraints. $^{24}$ We take an agnostic view and investigate its linear effect on the total sample. The next variable used is a measure of financial development at a regional level findev ${ }_{i}$. This variable is calculated in Guiso, Zingales and Sapienza (2004) and it measures the likelihood that a consumer bank loan is denied in different Italian regions. The measured is "inverted" and normalized, so that a value of zero indicates the highest probability of denial and that the maximum possible value is 0.56 . We also include a number of variables that capture the reputation of the firm and the possible existence of relationship lending. These are a dummy variable that reflects whether the main office of the main lending bank of the firm is located in the same region as the headquarters of the firm main region $n_{i}$, the natural logarithm of the number of banks that the firm uses number of banks $s_{i t}$; the log of the age (in years) of the firm $a g e_{i t}$; the log of the length (in years) of the relationship with the main bank of the firm age relation ${ }_{i t}$, and the share of loans that the main bank has share $\operatorname{main}_{i t} .{ }^{25}$

We add three control variables, the logarithm of firm assets assets ${ }_{i t}$, leverage measured as total debt over total assets leverage ${ }_{i t}$, and the change in stocks and work in progress stock ${ }_{i t}$. These variables should jointly capture the size and level of activity of the firm. Finally, we include as additional control variables, the same ones that we use in section 4.3 (fixed capital $_{i t}$, sdsales ${ }_{i t}$ and growth assets ${ }_{i t}$ ) and sector specific year dummies to saturate the intercept of the regression at a sector-year level.

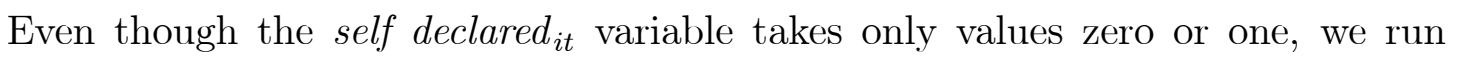
a standard linear regression to make it comparable with the instrumental variables approach that we use later on. Nevertheless the results are qualitatively very similar if we use a logit regression.

The results can be seen in the first column of Table 8. Firms with higher coverage ratio, higher net liquid assets, more financial development in their region and those with headquarters in the same region as the headquarters of their main bank are less likely to be financially constrained. The results on these four variables are sizeable

\footnotetext{
${ }^{24}$ See for example Almeida and Campello (2004).

${ }^{25}$ These last 4 variables are reported in the 1998 and 2001 qualitative surveys and their value only changes every three years.
} 
and highly significant. These variables are the ones that will be used in the next section as instruments to correct for potential answering biases in the self $_{\text {declared }}$ it $_{\text {t }}$ variable. The coefficients of the variables relative to reputation and relationship banking are also significant and take values that are consistent with some of the ideas in the relationship banking literature: a higher number of banks makes a firm more likely to be constrained. On the contrary, older firms and the ones with a longer bank relationship are also less likely to be constrained. It is beyond the scope of this paper to investigate the extent of relationship lending in Italy. Readers may find interesting the article by Detragiache, Garella and Guiso (2000) that does a more thorough analysis using this same dataset. ${ }^{26}$ Total leverage is negatively correlated with financing constraints, indicating that firms with less financing constraints in equilibrium do borrow more. Larger firms are also less financially constrained. This is a well known result and, for this reason, we use the size of the firm as an alternative measure of financing constraints. The growth rate of assets yields insignificant results and the accumulation of stocks, that often indicates a negative sales shock, is related to more financing constraints.

\section{Table 8 about here}

The model makes predictions about how employment decisions are related to the perceived financing constraints of firms. In this sense, the self declared ${ }_{i t}$ variable seems ideal as a proxy for $\overline{\lambda_{i}}$, the average intensity of financing constraints for firm $i$ in the simulated industry. However firms could have an incentive to overstate or understate their financing constraints. We control for this problem with an instrumental variable technique.

Instrumenting the financing constraints variable has the advantage of correcting for measurement errors and other potential endogeneity problems. However, it also means losing some information about financing constraints that is not contained in the observable variables used as instruments. Being able to use direct qualitative information is precisely one of the main advantages of using the self declared ${ }_{i t}$ measure with respect to other measures used in the literature. ${ }^{27}$ Therefore one can see the

\footnotetext{
${ }^{26}$ See also Boot (2000), Elyasiani and Goldberg (2004) and Ongena and Smith (2000).

${ }^{27}$ Papers such as Kaplan and Zingales (1997) and Fazzari, Hubbard and Petersen (1998) use objective balance sheet measures to construct indices as measures of financing constraints. In this
} 
instrumental variable approach as complementary to using the self declared it $_{\text {variable }}$ without instrumenting. The results in section 4.3 are robust to both specifications and reinforce each other.

The second column of Table 8 is the first stage of the instrumental variable regres-

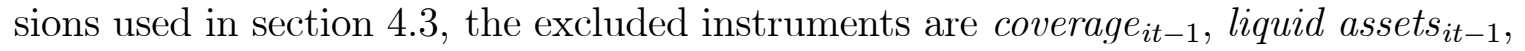
main region $_{i}$ and findev $_{i}$. The instruments that are time varying are lagged one period to reduce the possible effect of omitted variables affecting simultaneously the instruments and the dependent variable in the second stage. The R-squared of the excluded instruments is $4.4 \%$ which is relatively high considering that the total $\mathrm{r}$ squared of the first-stage regression is $5.8 \%$. The f-test of the joint significance of the omitted variables yields a value of 231 .

One possible concern with respect to the self declared ${ }_{i t}$ measure is that it could be correlated with the productivity shocks that the firm faces. If these productivity shocks affect the financing constraints that the firm faces through the channels included in the model (i.e. changes in the employment policies of firms induced by productivity shocks), this should not be a problem, as the calibration of the model makes predictions taking into account this potential reverse causality. However, one potential problem could be the presence in the constrained sample of distressed and poor performing firms. These firms may declare to be constrained simply because the banks judge them to be too risky and refuse them additional lending, even in the absence of any financing friction. We control for the potential bias induced by these firms in two ways: i) we include regressions where we use only the cross sectional instruments main region $i$ and findev $_{i}$. These instruments have the advantage that they are uncorrelated with any firm specific shock. The results of the first stage using these instruments are reported in column 3 of Table 8 . They have a lower explanatory power than the full set of instruments with a partial R-squared of the omitted instruments of $1.8 \%$ and a total R-squared of 3.1\%. Still, the F-test of the joint significance of the omitted instruments has a value of 158 which indicates quite a strong relationship. ii) In Appendix 4 we report the main coefficients of all the regressions estimated on a sample that excludes the worst performing firms. These

respect the IV regressions used here can be seen as similar to their approach, using a financing constraints index that is a weighted measure of coverage $_{i t-1}$, liquid assets $_{i t-1}$, main region $_{i}$ and findev $_{i}$ with the weights that produce the best possible match with the self declared ${ }_{i t}$ measure in an OLS regression. 
are identified as the firms that simultaneously belong to the bottom $5 \%$ quantile of the liquid assets $_{i t}$ variable and the bottom $5 \%$ quantile of the ratio of profit over assets. The results are robust to this exclusion and show that they are not driven by poor performing firms that declare to be financially constrained. ${ }^{28}$

Once we have established the validity of our main measure of financing constraints, we proceed, in the next section, to test the main predictions of the model.

\subsection{Results}

The first prediction of the model, that financially constrained firms hire a larger proportion of fixed-term employment with respect to permanent employment, is tested in Table 9. The ratio of fixed-term workers to permanent workers is regressed with respect to different measures of financing constraints, namely: a dummy variable that takes value one if the firm is small (column 1), the self declared ${ }_{i t}$ measure that captures the financing constraints that firms declare in the survey (column 2), the

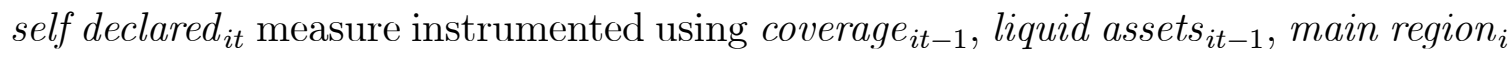
and findev $_{i}$ as instruments (column 3), and finally, the self declared it $_{\text {measure instru- }}$ mented using only the cross sectional instruments main region m $_{i}$ and findev (column 4). All the regressions include as control variables the volatility of sales, the amount of capital per worker, the yearly change in the assets of the firm, year and sector dummies.

\section{Table 9 about here}

The results in Table 9 show that smaller firms tend to use $1 \%$ more fixed-term contracts than larger firms. The results also point out in the same direction when using the self declared ${ }_{i t}$ measure and the instrumented versions of it, with uses of fixedterm contracts that range from $0.5 \%$ higher to $6 \%$ higher. This effect is statistically significant in all the regressions and also economically sizeable, given that the average use of fixed-term contracts in the sample is around 4\%. This result strongly supports the main prediction of the model, that fixed-term workers should be hired mostly by firms more subject to financing constraints. The model predicts that this happens because constrained firms use fixed-term contracts as a buffer that protects them

\footnotetext{
${ }^{28}$ The same result is obtained if we raise the threshold to exclude firms to $10 \%$ or $20 \%$,
} 
against the cost of firing or hoarding permanent workers in the future, conditional on a negative shock. The model also predicts that financially constrained firms should have a significantly higher volatility of total employment. This prediction is tested in Table 10. The dependent variable is the coefficient of variation of total employment, calculated on a three year window that coincides with each of the two waves of the six year period studied. The independent variables follow the same pattern as in Table 9.

\section{Table 10 about here}

The results show that smaller firms (column 1) have a smaller volatility of total employment. This goes against the predictions of the model, although the coefficient is only statistically significant at a $90 \%$ level and economically not very sizeable with smaller firms having a $0.1 \%$ lower employment volatility. A potential reason for this result is that problems of indivisibility (workers can only be fired one by one and not in fractions of a worker) may make a large proportion of the smaller firms of the sample keep a constant amount of workers throughout a three year window, while it is quite rare for larger firms to have a constant amount of workers for three consecutive years. If we exclude from the sample firms with coefficient of variation of total employment equal to zero, the coefficient for small firms becomes positive and significant at a $99 \%$ level with employment being $1.3 \%$ more volatile in small firms than in larger ones. ${ }^{29}$

Columns 2 to 4 show that the firms that declare themselves as constrained have a higher volatility of employment than unconstrained firms. The effect is very significant both in statistical terms and in terms of economic impact. Firms that declare to be financially constrained have a higher volatility of total employment of $1.3 \%$ up to $5 \%$ more depending on the specification. This is a large difference, given that the coefficient of variation of total employment for the full sample is $5.7 \%$.

The identification in tables 9 and 10 relies both on cross-sectional and time series variation, given that we use sector dummies but not firm specific fixed effects. Auxiliary regressions with standard firm fixed-effects and between groups estimators at a firm level show that, in fact, an important part of the effect is due to cross sectional variation.

\footnotetext{
${ }^{29}$ This regression is not reported, but all the details are available from the authors upon request.
} 
This higher volatility of total employment is partly a direct consequence of a higher use of fixed-term workers. The unconditional coefficient of variation of fixedterm workers is a full order of magnitude higher than the coefficient of variation of permanent workers, so a higher use of fixed-term contracts among constrained firms would mechanically imply a higher volatility of employment even if constrained and unconstrained firms were identical in terms of the volatility of each type of employment. However, the model predicts a higher individual volatility of each type of contract among constrained firms. To explore further this issue, in Table 11 we disentangle the effect of financing constraints on the volatility of each of the different types of employment. Columns 1 and 2 correspond to the dummy variable that distinguishes small firms, columns 3 and 4 to the self declared it $_{\text {measure. In the bottom }}$ section of the table, columns 5 and 6 correspond to the instrumented self declared it $_{\text {t }}$ variable using the full set of instruments, and columns 7 and 8 using only cross sectional instruments. Odd (even) columns have as dependent variable the coefficient of variation of fixed-term (permanent) employment. The coefficient of variation is not defined for firms that have zero workers of a particular type throughout the calculation period, it is also poorly defined when there is only one period with non-zero fixed-term workers. To minimize the effect of these firms, the coefficient of variation is calculated over the whole sample. Therefore, these are cross sectional measures and for this reason we perform between groups estimations. Still, the presence of firms with zero fixed-term workers throughout the sample is important. To avoid that the difference in results could be driven by a different sample in each regression, we restrict each sample to firms that have a valid observation in both the coefficient of variation of fixed-term employment and permanent employment.

\section{Table 11 about here}

The results in column 1 show that fixed-term contracts are more volatile among firms that are small and therefore more prone to experience financing constraints. The point estimate of the coefficient of variation of permanent contracts in column 2 is also positive, but a full order of magnitude smaller, and also, statistically not different from zero. The results in columns 3 and 4 show that firms that declare to be financially constrained have a higher volatility of permanent employment. The point estimate of the volatility of fixed-term contracts is positive and larger than the point 
estimate for permanent contracts, but the coefficient is not statistically significant. This same pattern is repeated in columns 5 and 6 . Finally columns 7 and 8 yield results that are too imprecise. Overall, the results in Table 11 show that the higher volatility of total employment among constrained firms identified in Table 10 is due to both types of contracts being more volatile for constrained firms. The table also has some suggestive evidence showing that a larger share of this effect may be due to the higher volatility of fixed-term workers, but the results in this respect are relatively weak.

The model also predicts that the number of firms using zero fixed-term contracts should be higher among firms that are unconstrained. This prediction constitutes an important test of the validity of the model, because the presence of a large share of firms that do not hire fixed-term workers is a constant feature of our sample. The simulated industry also shows a large average share of firms with zero fixed-term workers, quite similar to the one observed in the data despite this statistic is not explicitly matched in the calibration of the model.

To test this prediction, in Table 12 we show probit regressions where the dependent variable non zeroFT $T_{i t}$ is equal to 1 if the firm $i$ used any fixed-term contracts in period $t$ and is equal to zero otherwise. In column 1 the independent variables are self declared $_{i t}$ and the same controls as in the previous regressions. In column 2 we add, as an additional control, the log of assets for firm $i$ in period $t$.

\section{Table 12 about here}

The results show a higher likelihood of using fixed-term contracts among constrained firms. The result is robust to the inclusion of the log of total assets as an additional control. However, the control variable that measures the size of the firm indicates that large firms are also more likely to use fixed-term contracts. The number of zero fixed-term workers may be negatively related to size because of an indivisibility problem that is unrelated to financing constraints. This is because it is more likely that in a large firm there is at least one particular task that requires a temporary worker and therefore a fixed-term contract is used. Also, large firms are normally multi plant, while smaller firms are more likely to be single plant. Therefore the likelihood that at least one plant of a large firm hires some fixed-term workers may be higher than the likelihood for a small single plant firm. 
Columns 3 and 4 in Table 12 perform the same regressions as columns 1 and 2, but restricting the sample to observations in which the firms increased their level of total employment with respect to the previous year. The reason for this specification is related to the prediction of the model that constrained and unconstrained firms should behave differently when hiring and firing. The results show that conditional on hiring constrained firms are much more likely to hire fixed-term workers than unconstrained firms. This result can be interpreted in relationship with expression (21) that shows that, if we consider the hiring decision as a sequential one, all firms start hiring permanent workers and at some point they start hiring fixed-term workers. However, constrained firms tend to hire fixed-term workers earlier than unconstrained ones. When firing, all firms start firing their permanent workers and, if necessary, they fire permanent workers once they have fired all the temporary ones.

The model also predicts that most of the difference in the hiring behaviour of constrained versus unconstrained firms is driven by the behaviour of hiring firms (see table 4). In order to test this prediction in Table 13 we introduce dummy variables that splits the sample between firms that have hired additional workers over the last year ( hire $_{i t}$ ), firms that have reduced their amount of workers from the previous year ( fire $_{i t}$ ) and firms that keep the same amount of total employment as in the previous year (neutral ${ }_{i t}$ ). We then interact these dummy variables with the self declared ${ }_{i t}$ variable to see the different effect of financing constraints in each situation. In this regression also the control variable growth assets $s_{i t}$ is interacted with the three employment dummies, because we want to distinguish the behaviour driven by changes in employment from the behaviour driven by changes in the total assets of the firm.

Columns 1 and 2 include only firms that either hire or fire, columns 3 and 4 include also firms that neither hire or fire. Odd columns show the regressions using self declared $_{i t}$ as the explanatory variable, while even columns show the regressions where self declared ${ }_{i t}$ is instrumented using the full set of financial variables. These instruments are also interacted with the dummy variables hire $_{i t}$, fire it $_{\text {, neutral }}$ to give more flexibility to the first stage of the regression.

\section{Table 13 about here}

The results confirm the prediction that most of the effect of constrained firms 
using a higher amount of fixed-term workers is the result of these firms using them more when they are hiring new workers. This result is consistent across all four specifications, with a large and statistically significant effect. However, we do not find a significant empirical difference in the use of fixed-term workers of constrained firms that are not hiring additional workers.

The coefficient of hire $_{i t}$ is not statistically significant, while the coefficient fire $_{i t}$ is significantly negative in columns 1 and 2. In the simulated regressions in table 4 these coefficients represent the average ratio of fixed-term over permanent workers for unconstrained firms that increase and reduce employment. However in table 13 the same coefficients have to be interpreted as deviations from the constant and the average effect implicit in all the other control variables and year and sector dummies. Therefore in this case the relevant prediction of the model is the fact that the coefficient of hire ${ }_{i t}$ should be significantly bigger than the coefficient on fire $e_{i t}$. One reason why the results do not show a statistically significant difference is that there is not enough variation within year and sector to estimate these variables with precision. ${ }^{30}$

The overall picture from the empirical results shows that financially constrained firms use a higher fraction of fixed-term contracts and have a higher volatility of total employment. The higher volatility of total employment is partly due to the unconditional higher volatility of fixed-term workers, but also to the fact that conditional on being financially constrained, both fixed-term contracts and permanent contracts are more volatile. Constrained firms use fixed-term contracts more often, and most of the difference in the usage of fixed-term workers by constrained and unconstrained firms is explained by the firms that increase employment. These results confirm the predictions of the calibrated model.

\section{Conclusions}

We propose a model to study the firing and hiring decisions of firms in the presence of financing constraints and dual labour markets in which both fixed-term contracts and permanent contracts coexist. The model shows that financial market imperfections

\footnotetext{
${ }^{30}$ In fact a less saturated regression similar to the one in column 1 but withour year and sector dummies yields very precise estimates with a coefficient for hire $e_{i t}$ of 0.040 and a coefficient for fire $_{i t}$ of 0.028 , being these coefficients statistically different from each other. Similar results apply to less saturated versions of the other speciffications. Details are available upon request.
} 
increase expected firing costs, thus making permanent contracts implicitly more expensive. In the presence of financing constraints a larger share of output fluctuations is absorbed by fixed-term contracts, that also represent a larger proportion of total employment.

We calibrate the model using a representative sample of Italian firms, and we simulate an artificial industry with many heterogeneous firms. First, we use these simulations to derive robust predictions about the relationship between financing constraints and employment decisions of firms, to be tested on the empirical sample. Second, we analyze the effect on the simulated industry of relaxing the borrowing constraints and of introducing fixed-term workers in an industry where only permanent workers were available. We show that the introduction of fixed-term contracts allows firms to better absorb productivity fluctuations. Moreover financially constrained firms not only hire more fixed-term workers, but also use them to absorb a larger part of total employment volatility. The consequence is that the introduction of fixed-term contracts makes permanent contracts of financially constrained firms less volatile then before.

We test the predictions of the model on our sample of Italian manufacturing firms. We consider several different measures of financing constraints: i) the size of firm; ii) a "self-declared" measure of financing constraints that is constructed using the direct qualitative information available in the Mediocredito survey; iii) an instrumented version of this measure. We use as instruments both firm financial variables and a measure of regional financial development. The estimation results confirm the predictions of the model. In particular financially constrained firms have a larger proportion of fixed-term contracts and a higher volatility of total employment. Both types of contract are more volatile among constrained firms.

Our results shed some light on the role of fixed-term contracts in absorbing productivity shocks in the presence of financing constraints. The firing costs associated to permanent contracts make them less likely to absorb employment fluctuations due to productivity shocks. We show that the presence of financing constraints emphasizes this effect not only by increasing the usage of fixed-term workers, but also by making fixed-term contracts more volatile.

The paper is also an interesting step forward in understanding how do financing constraints affect the real activity of firms. Previous literature has mainly concen- 
trated on the effect of financing constraints on fixed capital investment. We instead focus on the employment decision of firms. Importantly, we show that the interactions between financing frictions and employment decisions allow us to distinguish between the effect of current financing problems of firms from the effect of future expected financing constraints. The theoretical and empirical results of the paper confirm that, while a small fraction of firms is currently financially constrained at any point in time, future expected financing constraints matter for a much larger fraction of firms, and are in important factor in determining employment decisions.

The policy implications of our results are interesting. The introduction of fixedterm contracts helps firms to reduce their exposure to financing constraints, and makes total employment of financially constrained firms more volatile but permanent employment less volatile. Policies that relax financing constraints that firms face will have a positive impact on the stability of total employment and in particular on fixed-term contracts. Therefore policies that aim to reduce the financing constraints face by firms not only would decrease job instability in general, but would also help to close the gap in terms of job instability between fixed-term and permanent contracts.

\section{References}

[1] Almeida, E. and M. Campello, 2004, "The Cash Flow Sensitivity of Cash," Journal of Finance, vol. 59(4), 1777-1804.

[2] Almeida, E. and M. Campello, 2006, Financial Constraints, Asset Tangibility and Corporate Investment, mimeo, NBER W.P. n. 12087.

[3] Alonso-Borrego, C., Fernandez-Villaverde, J. and Galdón-Sánchez, J. E. (2004) "Evaluating Labor Market Reforms: A General Equilibrium Approach," IZA Working Paper N. 1129.

[4] Benito, A. and I. Hernando (2003) "Labour demand, flexible contracts and financial factors: new evidence from Spain". Banco de España working paper 0312

[5] Angelini, P. and A. Generale, (2005). "Firm Size Distribution: Do Financial Constraints Explain It All? Evidence From Survey Data," Temi di discussione (Economic working papers) 549, Bank of Italy, Economic Research Department. 
[6] Amuedo-Dorantes C. and M.A. Malo, (2005) "Are temporary work contracts used as a buffer against changing expectations? An Analysis of Gross Flows by Type of Work Contract". William Davidson Institute Working Paper Nba 646

[7] Ausubel, Lawrence M. (1991) "The Failure of Competition in the Credit Card Market," American Economic Review, Vol. 81, No. 1, pp. 50-81, March.

[8] Basile, R., Giunta, A. and J.B. Nugent, (2003) "Foreign Expansion by Italian Manufacturing Firms in the Nineties: An Ordered Probit Analysis," Review of Industrial Organization, 2003, 23, 1-24

[9] Bentolila,Samuel; Giles Saint Paul (1992) "The Macroeconomic Impact of Flexible Labor Contracts, with an Application to Spain," European Economic Review 36.

[10] Bentolila,Samuel and Giuseppe Bertola (1990) "Firing Costs and Labor Demand: How Bad is Eurosclerosis?" Review of Economic Studies 54.

[11] Blanchard Olivier and Augustin Landier (2002) "The Perverse Effects of Partial Labour Market Reform: Fixed-Term Contracts in France," The Economic Journal, 112 (June)

[12] Boot, A. W. A. (2000), 'Relationship banking: What do we know?', Journal of Financial Intermediation 9, 7-25.

[13] Caggese A., 2006, Testing Financing Constraints on Firm Investment Using Variable Capital, Pompeu Fabra University working paper

[14] Cipollone, P. and A. Guelfi, 2003, "Tax Credit Policy and Firms' Behaviour: the Case of Subsidy to Open-end Labour Contract in Italy," Economic working paper n.471, Bank of Italy, Economic Research Department.

[15] Detragiache, E., Garella, P. and L. Guiso, 2000, "Multiple versus Single Banking Relationships: Theory and Evidence," Journal of Finance, vol. 55(3), pages 11331161, 06.

[16] Dolado, Juan J.; Carlos García-Serrano and Juan F. Jimeno (2002) "Drawing Lessons from the Boom of Temporary Jobs in Spain," The Economic Journal, 112 (June)

[17] Elyasiani, E. and Goldberg, L. G., (2004) 'Relationship lending: a survey of the literature', Journal of Economics and Business 56(4), 315-330.

[18] Fazzari, S., R.G. Hubbard and B. Petersen, (1988) Financing constraints and corporate investment, Brookings Papers on Economic Activity 1, 141-195. 
[19] García-Serrano, C., (1998) "Worker Turnover and Job Reallocation: the Role of Temporary Contracts" Oxford Economic Papers, 50: 709-725.

[20] Guiso, L., Sapienza, P. and L. Zingales, 2002, "Does Local Financial Development Matter?", NBER Working Papers n.8923.

[21] Hennessy, C., Levy, A. and T. Whited, 2006," Testing Q Theory with Financing Frictions", Forthcoming, Journal of Financial Economics.

[22] Hennessy, C. and T. Whited, 2006, "How Costly is External Financing? Evidence from a Structural Estimation", forthcoming, Journal of Finance.

[23] Hopehayn and Rogerson (1993) "Job Turnover and Policy Evaluation: A General Equilibrium Analysis," Journal of Political Economy, 101, 5, 915-938

[24] Hubbard, G.R., (1998) "Capital-Market Imperfections and Investment," Journal of Economic Literature 36, 193-225.

[25] Kaplan, Steven N., and Luigi Zingales, (1997) Do investment-cash flow sensitivitiesb provide useful measures of financing constraints?, Quarterly Journal of Economics 112, 169-215.

[26] Kugler, Adriana and Giovanni Pica, "Effects of Employment Protection and Product Market Regulations on the Italian Labor Market," forthcoming in J. Messina, C. Michelacci, J. Turunen, and G. Zoega, eds., "Labour Market Adjustments in Europe," Edward Elgar.

[27] Nickell, Stephen; Nicolitsas, D. (1999) "How Does Financial Pressure Affect Firms?' European Economic Review 43, no. 8 (1999), p. 1435

[28] Ongena, S. and Smith, D. (2000), 'Bank relationships: a survey', In P. Harker and S.A. Zenios (eds), The Performance of Financial Institutions, Cambridge University Press .

[29] Piga, G., (2002) "Debt and Firms' Relationships: The Italian Evidence,," Review of Industrial Organization, 20, 267-82.

[30] Rendon, Silvio (2005) "Job Creation and Investment in Imperfect Capital and Labor Markets" Mimeo ITAM

[31] Saint-Paul, G. (1996), "Dual labor markets, a macroeconomic perspective," Cambridge,MA: MIT Press.

[32] Smolny, W.; Winker, P.(1999) "Employment Adjustment and Financing Constraints," Dept. of Economics, University of Mannheim, Discussion Paper, Nr. 573-99, 1999 
[33] Stiglitz, Joseph E.; Andrew Weiss, (1981) "Credit Rationing in Markets with Imperfect Information," American Economic Review, June 1981, v. 71, iss. 3, pp. 393-410

[34] Whited, T., (2006) "External Finance Constraints and the Intertemporal Pattern of Intermittent Investment," Forthcoming, Journal of Financial Economics.

\section{Appendix 1}

In this section we show that the normalization of wages of both fixed-term and permanent workers being equal to one is without loss of generality and simply indicates that the amount of labour force of each type is measured in the model in monetary units.

Consider a more general model in which labour is measured in worked hours and the hourly wages for fixed-term and for permanent workers are $w^{f}$ and $w^{p}$ respectively. Both wages are assumed to be constant over time.

Let $l_{t}^{\prime p}$ and $l_{t}^{\prime f}$ denote the number of total hours worked by permanent and fixedterm workers respectively. Following the same structure as in expressions (2) and (4) The production function in which labour is measured in hours can be expressed as:

$$
y_{t}=\theta_{t}^{\prime}\left(l_{t}^{\prime p}+\rho^{\prime} l_{t}^{\prime f}\right)^{\alpha} \quad \text { with } \quad 0<\rho^{\prime}<1 ; 0<\alpha<1
$$

Where $\rho^{\prime}$ measures the difference in productivity per hour worked of each type of contract and $\theta_{t}^{\prime}$ the productivity level per hour of permanent labour worked. The parameter $\alpha$ is identical to the one in equation (2). The budget constraint of the firm can be written as:

$$
d_{t}+w^{p} l_{t+1}^{p}+w^{f} l_{t+1}^{\prime f}-F i_{t}^{p} S_{t}=a_{t}+\frac{b_{t}}{R}
$$

We introduce the following changes of variables: $l_{t}^{p}=w^{p} l_{t}^{p}$ and $l_{t}^{f}=w^{f} l_{t}^{\prime f}$, which indicate that labour is now measured in total monetary units paid and not in worked hours. The new budget constraint is therefore identical to the one in equation (4). The production function becomes:

$$
y_{t}=\theta_{t}^{\prime}\left(\frac{l_{t}^{p}}{w^{p}}+\rho^{\prime} \frac{l_{t}^{f}}{w^{f}}\right)^{\alpha} \quad \text { or equivalently } \quad y_{t}=\frac{\theta_{t}^{\prime}}{w^{p^{\alpha}}}\left(l_{t}^{p}+\rho^{\prime} \frac{w^{p}}{w^{f}} l_{t}^{f}\right)^{\alpha}
$$

Now we can introduce two further changes of variable $\theta_{t}=\frac{\theta_{t}^{\prime}}{w^{p^{\alpha}}}$ and $\rho=\rho^{\prime} \frac{w^{p}}{w^{f}}$ to reach expression (2), in which the productivity parameter $\theta_{t}$ is re-scaled to reflect productivity per unit of pay of a permanent worker and $\rho$ reflects the productivity differential between fixed-term and permanent workers net of their wage differential. Recall that the model requires that $\rho=\rho^{\prime} \frac{w^{p}}{w^{f}}$ is smaller than one. There are several combinations of wages and productivity that can achieve this result. For example 
fixed-term and permanent workers could be equally productive per hour, but fixedterm workers may require a wage differential to compensate for a higher job instability. Another possibility would be that fixed-term workers are paid less than permanent workers due to labour market frictions and they are less productive per hour worked, with the productivity differential being larger than the wage differential. This second possibility is the most likely one in the Italian case, given that the unconditional wage ratio $\frac{w^{p}}{w^{f}}$ is 1.35 according to the OECD. ${ }^{31}$

\section{Appendix 2}

In this section we illustrate a proof of proposition 1 .

Using the definition of $\Omega_{t}$ in equation (13), we define $E_{t}\left(\Omega_{t+1}\right)$ as follows:

$$
E_{t}\left(\Omega_{t+1}\right)=E_{t}\left[\left(F-\mu_{t+1}\right) S_{t+1}\right]+E_{t}\left(\mu_{t+1}\right)
$$

Conditional on $a_{t}$ and $l_{t+1}^{p}$, the realization of the shock $\theta_{t+1}$ determines $a_{t+1}$ and the policy functions $\mu_{t+1}\left(\theta_{t+1} \mid a_{t}, l_{t+1}^{p}\right), S_{t+1}\left(\theta_{t+1} \mid a_{t}, l_{t+1}^{p}\right)$ and $l_{t+2}^{p}\left(\theta_{t+1} \mid a_{t}, l_{t+1}^{p}\right)$. Therefore the value of $E_{t}\left(\Omega_{t+1}\right)$ can be defined as follows:

$E_{t}\left(\Omega_{t+1}\right)=\sum_{j=1}^{N} \Gamma\left(\theta_{t+1} / \theta_{t}\right)\left\{\left[F-\mu_{t+1}\left(\theta_{t+1} \mid a_{t}, l_{t+1}^{p}\right)\right] S_{t+1}\left(\theta_{t+1} \mid a_{t}, l_{t+1}^{p}\right)+\mu_{t+1}\left(\theta_{t+1} \mid a_{t}, l_{t+1}^{p}\right)\right\}$

Moreover we define $\theta_{A}$ as the minimum value of $\theta_{t+1}$ such that the firm hires more permanent workers and $\theta_{B}$ as the minimum value of $\theta_{t+1}$ such that the firm does not fire permanent workers. Assuming that $A>B>1$, equation (31) can be defined as follows:

$$
E_{t}\left(\Omega_{t+1}\right)=F \sum_{j=1}^{B-1} \Gamma\left(\theta_{t+1} / \theta_{t}\right)+\sum_{j=B}^{A-1} \Gamma\left(\theta_{t+1} / \theta_{t}\right) \mu_{t+1}\left(\theta_{t+1} \mid a_{t}, l_{t+1}^{p}\right)
$$

We can use equation (32) to interpret the effect of $l_{t+1}^{p}$ on $E_{t}\left(\Omega_{t+1}\right)$. We define $\widehat{l}_{t+2}^{p}\left(\theta_{t+1} \mid a_{t}\right)$ as the optimal amount of permanent workers in period $t+1$ if the firing costs do not apply in that period only. The assumptions about the production function imply that $\widehat{l}_{t+2}^{p}$ is increasing in $\theta_{t+1}$, and that $\widehat{l}_{t+2}^{p}\left(\theta_{1} \mid a_{t}\right)>0$. Suppose now that $l_{t+1}^{p}=0$. In this case $A=B=1$ and $E_{t}\left(\Omega_{t+1}\right)=0$. As $l_{t+1}^{p}$ increases, eventually $(1-\delta) l_{t+1}^{p}$ becomes larger than $\widehat{l}_{t+2}^{p}\left(\theta_{1} \mid a_{t}\right)$ and $A$ becomes larger than 1 . This implies that $E_{t}\left(\Omega_{t+1}\right)$ becomes positive and equal to $\sum_{j=1}^{A} \Gamma\left(\theta_{t+1} / \theta_{t}\right) \mu_{t+1}\left(\theta_{t+1} \mid a_{t}, l_{t+1}^{p}\right)$. As $l_{t+1}^{p}$ further increases, there are Four possibilities:

\footnotetext{
${ }^{31}$ To our knowledge there is no paper that calculates this wage differential conditional on observables.
} 
i) $A$ and $B$ do not change. In this case $E_{t}\left(\Omega_{t+1}\right)$ increases because

$\sum_{j=1}^{A} \Gamma\left(\theta_{t+1} / \theta_{t}\right) \mu_{t+1}\left(\theta_{t+1} \mid a_{t}, l_{t+1}^{p}\right)$ increases in $l_{t+1}^{p}$, due to the fact that $\mu_{t+1}$ increases.

ii) $A$ increases, $B$ does not change. In this case $E_{t}\left(\Omega_{t+1}\right)$ increases. The effect described in (i) is still at work. In addition now $\mu_{t+1}$ is positive for a wider range of values of $\theta$.

iii) $B$ increases, $A$ does not change. In this case $E_{t}\left(\Omega_{t+1}\right)$ increases. The effect described in (i) is still at work. In addition now for some values of $\theta$ the firm fires the workers. Conditional on these outcomes $E_{t}\left(\Omega_{t+1}\right)$ increases by $F$ rather than by $\mu_{t+1}\left(\theta_{t+1} \mid a_{t}, l_{t+1}^{p}\right)$. Since $F$ is the upper bound to $\mu$, this increases $E_{t}\left(\Omega_{t+1}\right)$.

iv) Both $A$ and $B$ increase. In this case the effects described in (i), (ii) and (iii) are contemporaneously at work, and $E_{t}\left(\Omega_{t+1}\right)$ increases.

This proves proposition I.

\section{Appendix 3}

In this section we briefly describe a version of the model with a non stationary productivity shock. First, we rewrite the production function as follows:

$$
\begin{aligned}
& y_{t}=\bar{\theta}_{t}^{1-\alpha}\left(l_{t}^{p}+\rho l_{t}^{f}\right)^{\alpha} \\
& 0<\rho<1 ; 0<\alpha<1
\end{aligned}
$$

where:

$$
\bar{\theta}_{t} \equiv \theta_{t}^{\frac{1}{1-\alpha}}
$$

Then we assume that the productivity shock $\theta_{t}$ is non stationary:

$$
\log \theta_{t}=\log \theta_{t-1}+\log \varepsilon_{t}
$$

Where $\varepsilon_{t}$ is a stationary and possibly persistent stochastic process. It follows that also $\bar{\theta}_{t}$ is a non stationary stochastic process:

$$
\log \bar{\theta}_{t}=\log \bar{\theta}_{t}+\frac{1}{1-\alpha} \log \varepsilon_{t}
$$

Therefore:

$$
\frac{\bar{\theta}_{t}}{\bar{\theta}_{t-1}}=\varepsilon_{t}^{\frac{1}{1-\alpha}}
$$


By dividing both sides of equation (33) by $\bar{\theta}_{t-1}$, we obtain a stationary transformation of the production function:

$$
\begin{gathered}
\widehat{y}_{t}=\varepsilon_{t}\left(\widehat{l}_{t}^{p}+\rho \widehat{l}_{t}^{f}\right)^{\alpha} \\
\widehat{y}_{t} \equiv \frac{y_{t}}{\bar{\theta}_{t-1}} ; \widehat{l}_{t}^{p} \equiv \frac{l_{t}^{p}}{\bar{\theta}_{t-1}} ; \widehat{l}_{t}^{f} \equiv \frac{\widehat{l}_{t}^{f}}{\bar{\theta}_{t-1}}
\end{gathered}
$$

Therefore the firm's problem can be reformulated in terms of stationary variables:

$$
V_{t}\left(\widehat{l}_{t}^{p}, \varepsilon_{t}, \widehat{a}_{t}\right)=\max _{\left\{\widehat{l}_{t+1}^{p}, \widehat{l}_{t+1}^{f}, \widehat{b}_{t}\right\}} \widehat{d}_{t}+\frac{1}{R} E_{t}\left[V_{t+1}\left(\widehat{l}_{t+1}^{p}, \varepsilon_{t+1}, \widehat{a}_{t+1}\right)\right]
$$

This transformed problem can be solved in the same way as the original problem, and yields similar predictions. Importantly, the key prediction of the model hold true for both the original and the transformed variables. For instance, the optimal ratio between the transformed variables predicted by the model, $\widehat{l}_{t}^{f} / \widehat{l}_{t}^{p}$, is by construction also equal to the optimal ratio between the original variables, $l_{t}^{f} / l_{t}^{p}$.

Moreover also the predictions about the volatility of employment for constrained and unconstrained firms are likely to be robust to the presence of a non-stationary shock. As an illustration, consider the following approximation of the average value of $\widehat{l}_{t}^{f}$ :

$$
\overline{\bar{l}}_{t}^{f}=\sum_{t=1}^{T} \frac{l_{t}^{f}}{T}\left(\frac{1}{\bar{\theta}_{t-1}}\right) \approx(1 / \overline{\bar{\theta}}) \sum_{t=1}^{T} \frac{l_{t}^{f}}{T}
$$

Where $\overline{\vec{l}}_{t}^{f}$ is the average value of $\widehat{l}_{t}^{f}$ for a generic firm, and $\overline{\bar{\theta}}$ is the average value of $\bar{\theta}_{t}$ during the sample period. Under this approximation, it follows that the coefficient of variation of $\widehat{l}_{t}^{f}$ is the same as the coefficient of variation of the original variable $l_{t}^{f}$. This approximation is reasonable when we interpret our empirical data, because the sample period is very short. Nonetheless it is the less accurate the more $\theta_{t}$ grows or shrinks during the sample period for a firm. In order to control for this problem, in the empirical section we include the growth of assets of the firms as a regressor in the estimations of the coefficients of variation, and we show that the main results are not sensitive to the inclusion or exclusion of this variable.

\section{$9 \quad$ Appendix 4}

In this section we show the coefficients of the main regressions in the text excluding the additional control variables or excluding firms that belong simultaneously to the 
$5 \%$ bottom quantile of the average value of net liquid assets and profits over assets.

Coefficients of regressions on the constraint variables excluding all the control variables except year and sector dummies

Dependent Variable

\begin{tabular}{|c|c|c|c|c|c|}
\hline \multicolumn{5}{|l|}{ Independent Variable } & non zeroFT $i t$ \\
\hline dirmmur if amoll. & $0.0086^{* * *}$ & $-0.0021^{* *}$ & 0.0049 & $0.0867^{* *}$ & 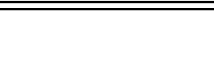 \\
\hline aummy il smallit & {$[0.0020]$} & {$[0.0010]$} & {$[0.0048]$} & {$[0.0419]$} & - \\
\hline & $0.0069^{* * *}$ & $0.0135^{* * *}$ & $0.0190^{* * *}$ & 0.0126 & $0.1270^{* * *}$ \\
\hline seli declared $i t$ & {$[0.0027]$} & {$[0.0010]$} & {$[0.0051]$} & {$[0.0435]$} & {$[0.0356]$} \\
\hline self declared $_{i t}$ & $0.0265^{* *}$ & $0.0469^{* * *}$ & $0.0743^{* * *}$ & 0.1892 & \\
\hline (full IV) & {$[0.0124]$} & {$[0.0058]$} & {$[0.0209]$} & {$[0.1737]$} & - \\
\hline self declared $_{i t}$ & $0.0551^{* * *}$ & $0.0396^{* * *}$ & $0.0236^{* * *}$ & 0.1589 & \\
\hline (cross sectional IV) & {$[0.0191]$} & {$[0 . .0099]$} & {$[0.0432]$} & {$[0.3623]$} & - \\
\hline
\end{tabular}

Coefficients of regressions on the constraint variables excluding firms that belong simultaneously to the $5 \%$ bottom quantile of net liquid assets and profits over assets

Dependent Variable

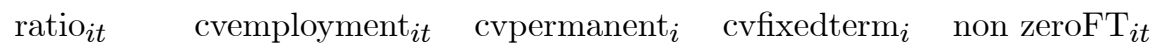

Independent Variable

\begin{tabular}{|c|c|c|c|c|c|}
\hline dur opoll & $0.0066^{* * *}$ & $2-0.0038^{* * *}$ & -0.0004 & $0.0720^{*}$ & \\
\hline dummy if smallit & {$[0.0019]$} & {$[0.0010]$} & {$[0.0049]$} & {$[0.0420]$} & - \\
\hline \multirow{2}{*}{ self declared $_{i t}$} & $0.0056^{* * *}$ & $0.0134^{* * *}$ & $0.0222^{* * *}$ & 0.0348 & $0.1137^{* * *}$ \\
\hline & {$[0.0024]$} & {$[0.0012]$} & {$[0.0054]$} & {$[0.0469]$} & {$[0.0355]$} \\
\hline self declared $_{i t}$ & $0.0233^{*}$ & $0.0468^{* * *}$ & $0.0755^{* * *}$ & 0.1208 & \\
\hline (full IV) & {$[0.0125]$} & {$[0.0058]$} & {$[0.0232]$} & {$[0.1968]$} & - \\
\hline self declared $_{i t}$ & $0.0529^{* * *}$ & $0.0397^{* * *}$ & -0.0465 & 0.2952 & \\
\hline (cross sectional IV) & {$[0.0192]$} & {$[0 . .0099]$} & {$[0.0485]$} & {$[0.4086]$} & - \\
\hline
\end{tabular}


Figure 1: Elasticity of the ratio of fixed term workers to permanent workers with respect to the borrowing limit

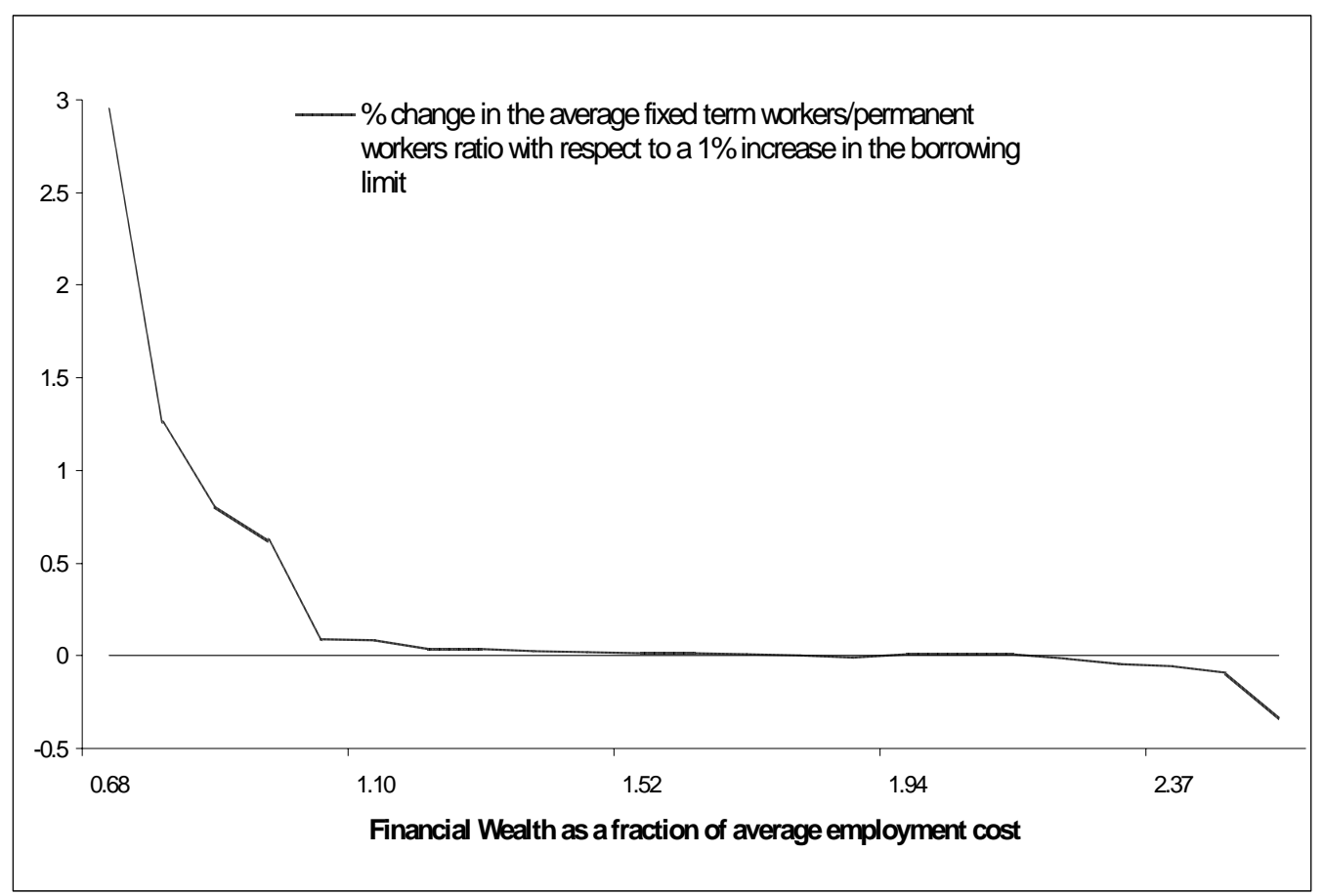

\section{Tables and Figures}

Table 1: Calibration

\begin{tabular}{l|c||c||cc}
\hline \hline & Parameter values & Empirical restriction & \multicolumn{2}{|c}{ Matched moments } \\
\hline \hline$r$ & & & Data & Model \\
$\alpha$ & 0.03 & Real interest rate & 0.03 & 0.03 \\
$\rho$ & 0.95 & Returns to scale & 0.95 & 0.95 \\
$\delta$ & 0.985 & Average ratio (fixed-term/permanent) & 0.038 & 0.040 \\
$v$ & 0.022 & Retirement of permanent workers & 0.022 & 0.022 \\
$\sigma_{P}$ & 0.92 & average(gross hiring/employment) & 0.102 & 0.084 \\
$\sigma_{I}$ & 0.032 & std(hiring/employment) & 0.175 & 0.183 \\
$\bar{b}$ & 0.22 & Std.(sales/assets) & 0.283 & 0.239 \\
$F$ & $0.13^{*}$ & \% of financially constrained observations & $16 \%$ & $14.5 \%$ \\
$\gamma$ & $0.10^{* *}$ & Average job destruction rate & 0.084 & 0.078 \\
\hline \hline & 0.96 & Average age & 24 & 25 \\
\hline \hline & & Other moments & Data & Model \\
\hline$*$
\end{tabular}

* The value of $\bar{b}$ is measured as a fraction of the average employment cost for one simulated firm. ** the firing cost $\mathrm{F}$ is expressed as a fraction of the yearly wage. 
Table 2: Predictions of the Model.

\begin{tabular}{l||cc|c||c}
\hline \multicolumn{1}{l||}{} & & & $\begin{array}{c}\% \text { diff. from } \\
\text { a simulated } \\
\text { panel of firms* }\end{array}$ \\
\hline Fixed term workers / Permanent workers & 0.055 & 0.033 & $67 \%$ & $148 \%$ \\
st. dev. employment / employment & 0.291 & 0.250 & $16 \%$ & $12 \%$ \\
st. dev. permanent workers / employment & 0.254 & 0.239 & $6.4 \%$ & $2.4 \%$ \\
st. dev. fixed-term workers / employment & 0.092 & 0.068 & $36 \%$ & $36 \%$ \\
st. dev. permanent workers / perm. workers & 0.266 & 0.244 & $8.8 \%$ & $3.1 \%$ \\
st. dev. fixed-term workers / f.t. workers & 0.528 & 0.391 & $35 \%$ & $24 \%$ \\
$\%$ of firms with no fixed-term workers & $68 \%$ & $82 \%$ & $-17 \%$ & $-16 \%$ \\
\hline \hline \% of firing of permanent workers & $0.35 \%$ & $0.80 \%$ & & \multicolumn{2}{||}{} \\
\% of hoarding of permanent workers & $12.9 \%$ & $12.5 \%$ & & \\
\hline
\end{tabular}

*These differences refer to a simulated balanced panel of firms. We calculate each statistic for 6 years of data for each firm.

This panel is sampled so that the average age of the firms is the same as the average age in the full sample and in the empirical data. Then we calculate the percentage difference between the cross sectional averages in the statistics for the constrained and the complementary sample.

Table 3: Different selection of the constrained group.

\begin{tabular}{l||c||c||cc}
\hline \hline & $\frac{\text { Fixed term workers }}{\text { Permanent workers }}$ & $\frac{\text { st. dev. empl. }}{\text { empl. }}$ & $\frac{\text { st. dev. perm. } w .}{\text { employment }}$ & $\frac{\text { st. dev. f.t. w. }}{\text { employment }}$ \\
\hline \hline 20\% most constrained firms & 0.057 & 0.2933 & 0.2473 & 0.098 \\
Complementary sample & 0.035 & 0.2484 & 0.2371 & 0.070 \\
\hline 33\% most c. firms (benchmark) & 0.055 & 0.2913 & 0.2548 & 0.092 \\
Complementary sample & 0.033 & 0.2508 & 0.2394 & 0.068 \\
\hline 50\% most constrained firms & 0.051 & 0.2841 & 0.2563 & 0.088 \\
Complementary sample & 0.029 & 0.2586 & 0.2470 & 0.066 \\
\hline 66\% most constrained firms & 0.047 & 0.2738 & 0.2528 & 0.082 \\
Complementary sample & 0.027 & 0.2578 & 0.2462 & 0.062 \\
\hline
\end{tabular}

Table 4: Differential Effect on Employment Volatilites

\begin{tabular}{rllcl}
\hline \hline \multicolumn{5}{c}{ Dependent variable: $\frac{\text { Fixed term workers }}{\text { Permanent workers }}$} \\
\hline \hline & $D_{i t}=1$ for & $D_{i t}=1$ for & $D_{i t}=1$ for & $D_{i t}=1$ for \\
& $20 \%$ most & $33 \%$ most & $50 \%$ most & $66 \%$ most \\
& constrained firms & constrained firms & constrained firms & constrained firms \\
\hline \hline constant & 0.000 & 0.000 & 0.000 & 0.000 \\
hire $_{i t} * D_{i t}$ & 0.043 & 0.047 & 0.050 & 0.053 \\
fire $_{i t} * D_{i t}$ & 0.004 & 0.008 & 0.009 & 0.009 \\
hire $_{i t}$ & 0.070 & 0.064 & 0.057 & 0.048 \\
fire $_{i t}$ & 0.021 & 0.019 & 0.017 & 0.016 \\
\hline \hline R-squared & 0.17 & 0.18 & 0.19 & 0.18 \\
\hline \hline
\end{tabular}


Table 5: Effect of the introduction of fixed term workers

\begin{tabular}{l||ccc||ccc||ccc}
\hline \multicolumn{1}{c||}{} & \multicolumn{3}{c||}{ All firms } & \multicolumn{3}{c||}{ Constr. firms } & \multicolumn{3}{c}{ Compl. sample } \\
\hline \hline fixed-term workers available & yes & no & $\% \Delta$ & yes & no & $\% \Delta$ & yes & no & $\% \Delta$ \\
Average value of $\phi_{t}$ & 0.045 & 0.040 & 12.5 & 0.096 & 0.083 & 15.6 & 0.020 & 0.018 & 11.1 \\
st. dev. employment / employment & 0.270 & 0.257 & 5.1 & 0.291 & 0.277 & 5.1 & 0.251 & 0.240 & 4.6 \\
st. dev. permanent workers / employment & 0.254 & 0.257 & -1.1 & 0.255 & 0.277 & -7.9 & 0.239 & 0.240 & -0.4 \\
\% of firing of permanent workers & 0.65 & 0.92 & -29 & 0.35 & 0.66 & -47 & 0.80 & 1.06 & -24.5 \\
\% of hoarding of permanent workers & 12.57 & 13.74 & -8.5 & 12.9 & 15.0 & -14 & 12.5 & 13.1 & -4.6 \\
\hline
\end{tabular}

Table 6: Elasticity of employment to an increase in the borrowing limit

\begin{tabular}{l||cc|cc|c|cc}
\multicolumn{1}{c||}{} & \multicolumn{2}{c||}{ All firms } & \multicolumn{2}{c}{ Constr. } & \multicolumn{2}{c}{ Compl. s. } \\
\hline \hline fixed-term workers available & yes & no & yes & no & yes & no \\
\hline \hline \multicolumn{1}{l||}{ Statistic } & -0.127 & -0.364 & & & & \\
\hline fraction of financially constrained firms & 0.064 & n.a. & 0.215 & n.a. & -0.064 & n.a. \\
Fixed term workers / Permanent workers & -0.035 & -0.200 & -0.111 & -0.329 & 0.028 & -0.093 \\
st. dev. employment / employment & -0.033 & n.a. & -0.109 & n.a. & 0.026 & n.a. \\
st. dev. permanent workers / employment & -0.210 & n.a. & -0.328 & n.a. & -0.164 & n.a. \\
st. dev. fixed-term workers/fixed-term workers & -0.010 & 0.023 & -0.070 & 0.307 & 0.015 & -0.065 \\
\% of firing of permanent workers & -0.070 & 0.092 & -0.167 & 0.035 & -0.017 & 0.125 \\
\% of hoarding of permanent workers & 0.045 & n.a. & 0.050 & n.a. & 0.043 & n.a. \\
\% of firms with no f.t. workers
\end{tabular}


Table 7: Summary Statistics

All firms

self declared $i t=1$

\begin{tabular}{l|ccc|ccc} 
variable & Mean & Median & Std Dev & Mean & Median & Std Dev \\
\hline \hline & & & & & & \\
ratio $_{i t}$ & 0.039 & 0 & 0.117 & 0.050 & 0.000 & 0.133 \\
cv(employment $)_{i t}$ & 0.057 & 0.035 & 0.082 & 0.074 & 0.047 & 0.097 \\
cv(fixed-term $)_{i}$ & 0.671 & 0.469 & 0.708 & 0.661 & 0.469 & 0.680 \\
cv(permanent $_{i}$ & 0.071 & 0.043 & 0.102 & 0.084 & 0.056 & 0.103 \\
self declared $_{i t}$ & 0.16 & 0.00 & 0.37 & 1 & 1 & 0 \\
fixed capital $_{i t}$ & 59.2 & 36.2 & 91.8 & 59.6 & 35.9 & 78.7 \\
${\text { sd }\left(\text { sales }_{i t}\right.}_{\text {leverage }_{i t}}$ & 8114 & 1168 & 42077 & 3534 & 1043 & 8938 \\
assets $_{i t}$ & 0.376 & 0.405 & 0.257 & 0.394 & 0.433 & 0.274 \\
Non zero fixed-term $_{i t}$ & 9.12 & 8.89 & 1.36 & 8.88 & 8.74 & 1.18 \\
Growth assets $_{i t}$ & 0.346 & 0 & 0.495 & 0.406 & 0 & 0.491 \\
Return on Assets $_{i t}$ & 0.095 & 0.064 & 0.212 & 0.102 & 0.065 & 0.218 \\
\hline \hline
\end{tabular}

The variables are defined as follows: ratio is fixed-term employment divided by permanent employment; $\mathrm{cv}()$ refers to the coefficient of variation of the relevant variable defined as its standard deviation over a three year period divided by its mean over the same period; self declared is a dummy variable that takes value 1 if the firm declares to be constrained and zero otherwise; fixed capital is fixed assets of the firm divided by the number of employees; sdsales is the standard deviation of the sales of the firm; leverage is total debt divided by total assets; Non zero fixed-term is a dummy variable that takes value one if the firm uses some fixed-term workers and zero otherwise; Growth assets is the yearly growth rate of assets; return on Assets is profit before interest and taxes divided by total assets. 
Table 8: Financing Constraints Variable

1

Justify First Stage IV First Stage IV2

\begin{tabular}{|c|c|c|c|}
\hline $\operatorname{coverage}_{i t}^{\diamond}$ & $\begin{array}{r}-0.086^{* * *} \\
{[0.005]}\end{array}$ & $\begin{array}{r}-0.094^{* * *} \\
{[0.004]}\end{array}$ & \\
\hline $\operatorname{liquid}_{\text {assets }}^{\diamond}$ & $\begin{array}{r}-0.122^{* * *} \\
{[0.020]}\end{array}$ & $\begin{array}{r}-0.032^{* * *} \\
{[0.009]}\end{array}$ & \\
\hline findev $_{i}$ & $\begin{array}{r}-0.003^{* * *} \\
{[0.0002]}\end{array}$ & $\begin{array}{r}-0.003^{* * *} \\
{[0.0002]}\end{array}$ & $\begin{array}{r}-0.004^{* * *} \\
{[0.0002]}\end{array}$ \\
\hline main region $_{i}$ & $\begin{array}{r}-0.036^{* * *} \\
{[0.006]}\end{array}$ & $\begin{array}{r}-0.034^{* * *} \\
{[0.005]}\end{array}$ & $\begin{array}{r}-0.034^{* * *} \\
{[0.006]}\end{array}$ \\
\hline number of banks $i t$ & $\begin{array}{r}0.030^{* * *} \\
{[0.006]}\end{array}$ & & \\
\hline $\operatorname{age}_{i t}$ & $\begin{array}{l}-0.005 \\
{[0.004]}\end{array}$ & & \\
\hline age relation $_{i t}$ & $\begin{array}{r}-0.010^{* * *} \\
{[0.003]}\end{array}$ & & \\
\hline share main $_{i t}$ & $\begin{array}{r}0.0005^{* * *} \\
{[0.0001]}\end{array}$ & & \\
\hline leverage $_{i t}$ & $\begin{array}{r}-0.086^{* * *} \\
{[0.021]}\end{array}$ & & \\
\hline $\operatorname{assets}_{i t}$ & $\begin{array}{r}-0.029^{* * *} \\
{[0.003]}\end{array}$ & & \\
\hline stock $_{i t}$ & $\begin{array}{r}0.113^{* *} \\
{[0.054]}\end{array}$ & & \\
\hline fixed capital $_{i t}$ & & $\begin{array}{r}-0.0001^{* * *} \\
{[0.00003]}\end{array}$ & $\begin{array}{r}-0.00003 \\
{[0.00003]}\end{array}$ \\
\hline sdsales $_{i t}$ & & $\begin{array}{r}-4.0 \mathrm{E}-07^{* * *} \\
{[7.0 \mathrm{E}-08]}\end{array}$ & $\begin{array}{r}-4.0 \mathrm{E}-07^{* * *} \\
{[7.2 \mathrm{E}-08]}\end{array}$ \\
\hline growth in totalassets & & $\begin{array}{r}-0.00007 \\
{[0.0004]} \\
\end{array}$ & $\begin{array}{r}-0.00002 \\
{[0.0001]} \\
\end{array}$ \\
\hline Observations & 15731 & 19389 & 19396 \\
\hline R-squared & 0.071 & 0.060 & 0.031 \\
\hline R-squared of omitted instruments & & 0.046 & 0.016 \\
\hline F-test of joint significance omitted instruments & & $231^{* * *}$ & $158^{* * *}$ \\
\hline
\end{tabular}

Standard errors in brackets* significant at $10 \%$; ${ }^{* *}$ significant at $5 \%$; $* *$ significant at $1 \%$. Dependent variable is self declared that takes value 1 if the firm declares to be constrained zero otherwise. Variables with superindex $\diamond$ are lagged one period in columns 2 and 3. Independent variables are: fixed capital - fixed assets of the firm divided by the number of employees; sdsales - standard deviation of the sales of the firm; growth assets - annual growth rate of assets; coverage - profits minus interest paid on debt over profits plus interest rate paid; liquid assets - bank deposits and cash over total assets; findev regional financial development; logarithm of firm assets; growsales - dummy if sales grew over the last year; leverage - total debt over total assets; stock - change in stocks and work in progress; number of banks number of banks that the firm uses; age - the log of the age (in years) of the firm ; age relation- the log of the length (in years) of the relationship with the main bank; share main- share of loans of the main bank; assets - (these last four variables only change every three years), year and sector dummies included in all the regressions. 
Table 9: Financing Constraints and Relative Use of Fixed-Term Contracts

123

3

\begin{tabular}{|c|c|c|c|c|}
\hline & size & self declared $_{i t}$ & self declared $_{i t}$ IV & self declared $_{i t}$ IV2 \\
\hline \multirow[t]{2}{*}{ dummy if constrained } & $\overline{0.010^{* * *}}$ & $0.005^{* *}$ & $0.031^{* *}$ & $0.058^{* * *}$ \\
\hline & {$[0.002]$} & {$[0.003]$} & {$[0.012]$} & {$[0.019$} \\
\hline \multirow[t]{2}{*}{ fixed capital $_{i t}$} & -0.00001 & $-0.00002^{* *}$ & $-0.00002^{* *}$ & $-0.00002^{* *}$ \\
\hline & {$[0.00001]$} & {$[0.00001]$} & {$[0.00001]$} & {$[0.00001]$} \\
\hline \multirow[t]{2}{*}{ sdsales $_{i t}$} & $1.1 \mathrm{E}-7^{* * *}$ & $1.1 \mathrm{E}-7^{* * *}$ & $1.1 \mathrm{E}-7 * * *$ & $1.2 \mathrm{E}-7^{* * *}$ \\
\hline & {$[2 \mathrm{E}-8]$} & {$[2 \mathrm{E}-8]$} & {$[2 \mathrm{E}-8]$} & {$[2 \mathrm{E}-8$} \\
\hline \multirow[t]{2}{*}{ growth in totalassets } & $0.019^{* * *}$ & -0.00006 & $0.017^{* * *}$ & $0.0160^{* * *}$ \\
\hline & {$[0.004]$} & {$[0.0004]$} & {$[0.004]$} & {$[0.004$} \\
\hline Observations & 11697 & 9429 & 11695 & 11697 \\
\hline R-squared & 0.109 & 0.104 & 0.099 & 0.073 \\
\hline
\end{tabular}

Standard errors in brackets. * significant at $10 \%$;* significant at $5 \%$; *** significant at $1 \%$. Dependent variable is the ratio of fixed-term workers to permanent workers. The dummy "if constrained" corresponds to small (value one if assets are smaller than 5700 million lira and zero otherwise) in column one and to self declared (value 1 if the firm declares to be constrained and zero otherwise) in columns 2 to 4 . The other independent variables are: fixed capital - fixed assets of the firm divided by the number of employees; sdsales - standard deviation of the sales of the firm; growth assets - annual growth rate of assets. Column 3 includes all all the instrumental variables and column 4 only the cross sectional ones; year and sector dummies included in all the regressions. 
Table 10: Financing Constraints and Employment Volatility

$1 \quad 2$

\begin{tabular}{|c|c|c|c|c|}
\hline & size & self declared $_{i t}$ & self declared $_{i t}$ IV & self declared $_{i t}$ IV2 \\
\hline \multirow[t]{2}{*}{ dummy if constrained } & 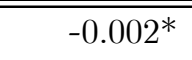 & $0.014^{* * *}$ & 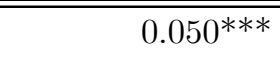 & $0.040^{* * *}$ \\
\hline & {$[0.001]$} & {$[0.001]$} & {$[0.006]$} & {$[0.009]$} \\
\hline \multirow[t]{2}{*}{ fixed capital $_{i t}$} & $0.00002^{* * *}$ & $0.00002^{* * *}$ & $0.00002^{* * *}$ & $0.00002^{* * *}$ \\
\hline & {$[6.0 \mathrm{E}-5]$} & {$[6.0 \mathrm{E}-5]$} & {$[6.0 \mathrm{E}-5]$} & [6.0E-5] \\
\hline \multirow[t]{2}{*}{ sdsales $_{i t}$} & $3 \mathrm{E}-7^{* *}$ & $3 \mathrm{E}-7 * * *$ & $5 \mathrm{E}-7 * * *$ & $5 \mathrm{E}-7^{* * *}$ \\
\hline & {$[1 \mathrm{E}-7]$} & {$[1 \mathrm{E}-7]$} & {$[1 \mathrm{E}-7]$} & {$[1 \mathrm{E}-7]$} \\
\hline \multirow[t]{2}{*}{ growth in totalassets } & $0.024^{* * *}$ & $0.024^{* * *}$ & $0.023^{* * *}$ & $0.024^{* * *}$ \\
\hline & {$[0.002]$} & {$[0.002]$} & {$[0.002]$} & {$[0.002]$} \\
\hline Observations & 18783 & 18783 & 18779 & 18783 \\
\hline R-squared & 0.017 & 0.023 & 0.028 & 0.005 \\
\hline
\end{tabular}

Standard errors in brackets. ${ }^{*}$ significant at $10 \% ; * *$ significant at $5 \%$; ** significant at $1 \%$. The dependent variable is the coefficient of variation of total employment. The dummy "if constrained" corresponds to small (value one if assets are smaller than 5700 million lira and zero otherwise) in column one and to self declared (value 1 if the firm declares to be constrained and zero otherwise) in columns 2 to 4 . The other independent variables are: fixed capital - fixed assets of the firm divided by the number of employees; sdsales - standard deviation of the sales of the firm; growth assets - annual growth rate of assets. Column 3 includes all all the instrumental variables and column 4 only the cross sectional ones; year and sector (defined as 2 digit ATECO91 classification) dummies included in all the regressions. 
Table 11: Differential Effect on Employment Volatilites

\begin{tabular}{|c|c|c|c|c|}
\hline & 1 & 2 & 3 & 4 \\
\hline & cv FT & cv Perm & cv FT & cv Perm \\
\hline \multirow{2}{*}{ dummy if constrained ${ }_{i t}$} & $0.089 * *$ & 0.004 & 0.024 & $0.019^{* * *}$ \\
\hline & {$[0.041]$} & {$[0.004]$} & {$[0.042]$} & {$[0.005]$} \\
\hline \multirow{2}{*}{ fixed capital $_{i t}$} & -0.0001 & $-2.3 \mathrm{E}-5$ & -0.0003 & -0.00001 \\
\hline & {$[0.0003]$} & {$[0.00003]$} & {$[0.0003]$} & {$[0.00003]$} \\
\hline \multirow[t]{2}{*}{ sdsales $_{i t}$} & $-1.2 \mathrm{E}-7$ & $-1 \mathrm{E}-8$ & $-1.8 \mathrm{E}-7$ & $-2 \mathrm{E}-8$ \\
\hline & {$[3.5 \mathrm{E}-7]$} & {$[4 \mathrm{E}-8]$} & {$[3.5 \mathrm{E}-7]$} & {$[4 \mathrm{E}-8]$} \\
\hline \multirow[t]{2}{*}{ growth in totalassets } & $-0.256^{* *}$ & $0.062^{* * *}$ & $-0.276^{* *}$ & $0.057 * * *$ \\
\hline & {$[0.121]$} & {$[0.014]$} & {$[0.122]$} & {$[0.014]$} \\
\hline Observations & 5580 & 5580 & 5580 & 5580 \\
\hline Number of firms & 1765 & 1765 & 1765 & 1765 \\
\hline R-squared & 0.120 & 0.039 & 0.118 & 0.046 \\
\hline
\end{tabular}

\begin{tabular}{l|rrrr} 
& 5 & 6 & 7 & 8 \\
& cv FT IV & cv Perm IV & cv FT IV2 & cv Perm IV2 \\
\hline \hline dummy if constrained $i t$ & 0.153 & $0.083^{* * *}$ & 0.018 & -0.033 \\
& {$[0.170]$} & {$[0.021]$} & {$[0.356]$} & {$[0.044]$} \\
fixed capital $_{i t}$ & -0.0003 & -0.00003 & -0.0003 & $-8.9 \mathrm{E}-6$ \\
& {$[0.0003]$} & {$[0.00004]$} & {$[0.0003]$} & {$[0.00004]$} \\
sdsales $_{i t}$ & $-1.2 \mathrm{E}-7$ & $-5 \mathrm{E}-8$ & $-1.9 \mathrm{E}-7$ & $-1 \mathrm{E}-8$ \\
& {$[3.6 \mathrm{E}-7]$} & {$[4 \mathrm{E}-8]$} & {$[3.6 \mathrm{E}-7]$} & {$[5 \mathrm{E}-8]$} \\
growth in totalassets $^{*}$ & $-0.304^{* *}$ & $0.044^{* * *}$ & $-0.276^{*}$ & $0.069^{* * *}$ \\
& {$[0.127]$} & {$[0.016]$} & {$[0.143]$} & {$[0.017]$} \\
\hline \hline Observations & 5578 & 5578 & 5580 & 5580 \\
Number of firms & 1765 & 1765 & 1765 & 1765 \\
R-squared & 0.113 & 0.015 & 0.027 & 0.002
\end{tabular}

Standard errors in brackets. $*$ significant at $10 \%$;* significant at $5 \%$; *** significant at $1 \%$. The dependent variables are the coefficient of variation of fixed-term and permanent employment. The dummy "if constrained" corresponds to small (value one if assets are smaller than 5700 million lira and zero otherwise) in column one and to self declared (value 1 if the firm declares to be constrained and zero otherwise) in columns 3 to 8 . The other independent variables are: fixed capital - fixed assets of the firm divided by the number of employees; sdsales - standard deviation of the sales of the firm; growth assets - annual growth rate of assets. Columns 5 and 6 include all the instrumental variables and columns 7 and 8 only the cross sectional ones; year and sector dummies included in all the regressions. 
Table 12: Likelihood of Unsing Fixed-Term Contracts (probit) 1

2 3

4

non zeroFT $i t$ non zeroFT $_{i t}$ if hire $=1$

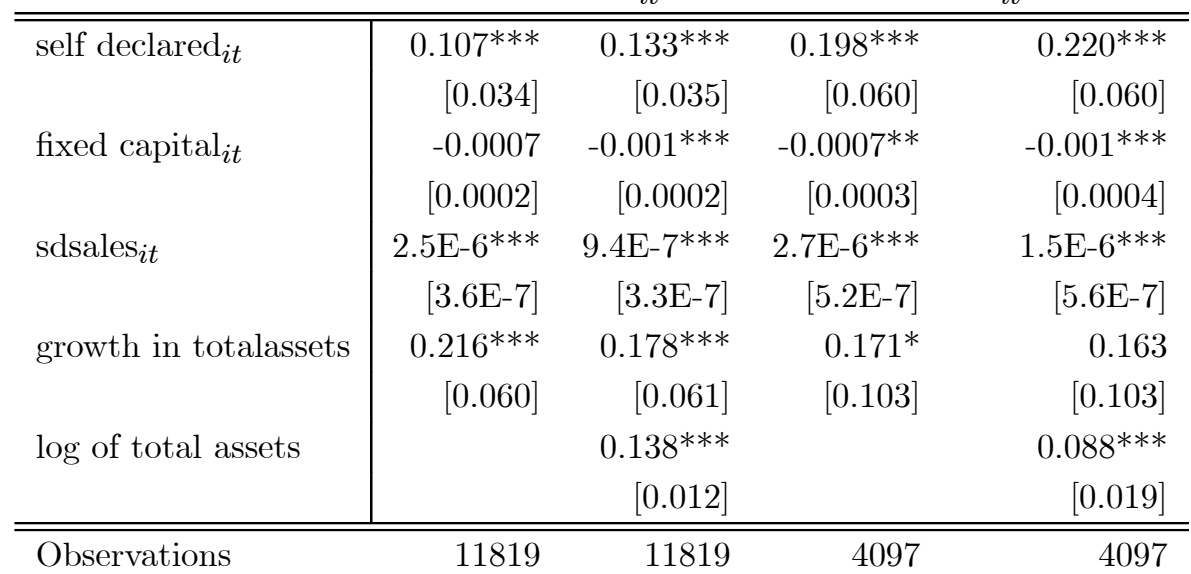

Standard errors in brackets. * significant at $10 \%$; ** significant at $5 \%$; *** significant at $1 \%$. Dependent variable is a dummy variable that takes value one if the firm has nonzero fixed-term workers the self declared variable takes value 1 if the firm declares to be constrained and zero otherwise. Columns 1 and 2 include all firms, columns 3 and 4 only firms that increased employment from the previous year. Other independent variables are: fixed capital - fixed assets of the firm divided by the number of employees; sdsales standard deviation of the sales of the firm; growth assets - annual growth rate of assets. year and sector dummies included in all the regressions. 
Table 13: Effect When Increasing or Reducing Total Employment

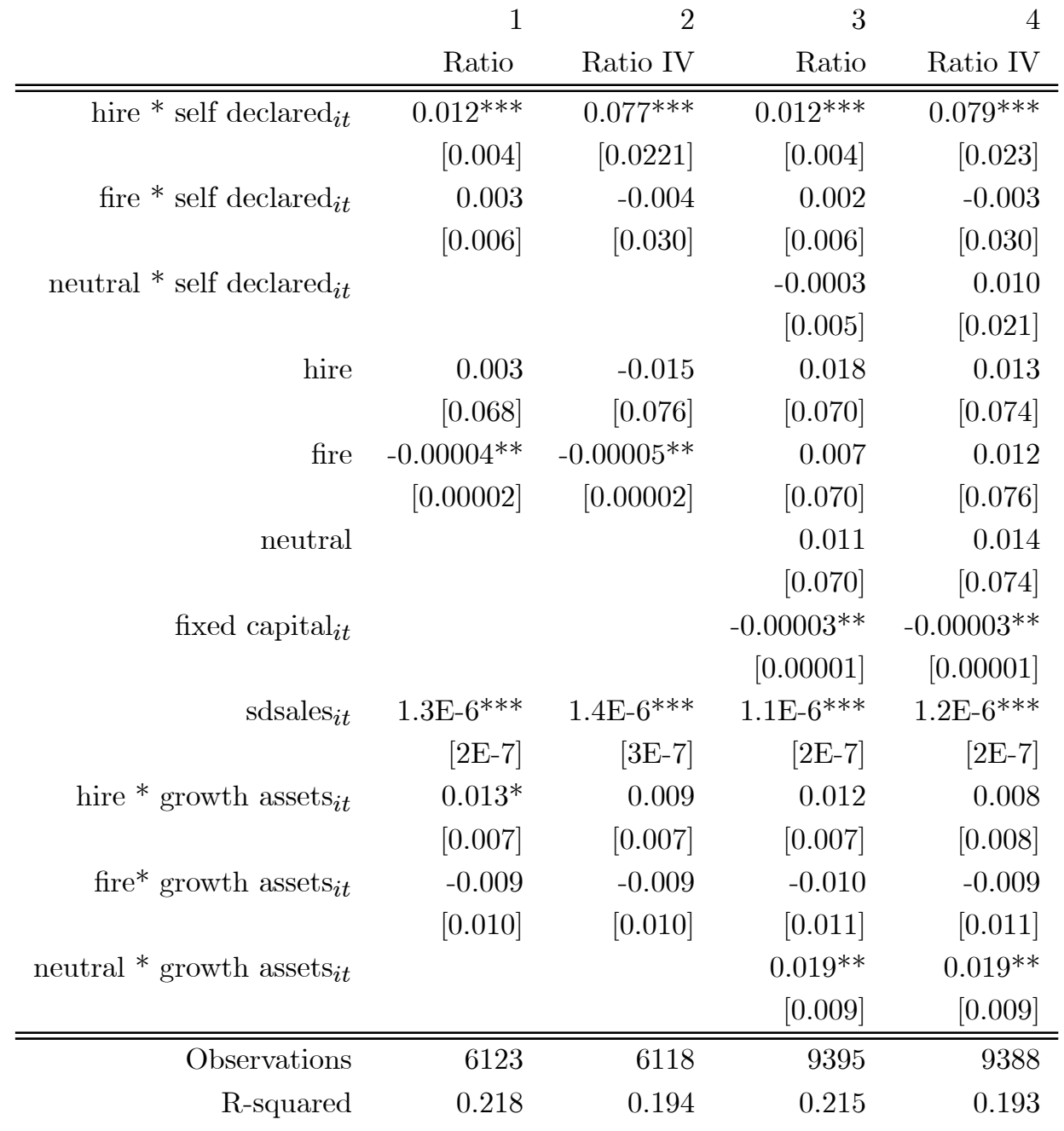

Standard errors in brackets. * significant at $10 \%$; ** significant at $5 \%$; *** significant at 1\%. Dependent variable is the ratio of fixed-term workers to permanent workers, the self declared measure takes value 1 if the firm declares to be constrained and zero otherwise. Hire, fire, neutral, are dummy variables that take value one if over the past year the firm is firing workers, hiring or keeping the same amount of workers respectively. Other independent variables are: fixed capital - fixed assets of the firm divided by the number of employees; sdsales - standard deviation of the sales of the firm; growth assets - annual growth rate of assets. Columns 2 and 4 include all the instrumental variables; year and sector dummies included in all the regressions. 